\title{
Accessing the Functional Capabilities of the Tick Microbiome Through Metagenomics
}

\author{
Darin Lee Shrewsberry Jr \\ West Virginia University, dlshrewsberry@mix.wvu.edu
}

Follow this and additional works at: https://researchrepository.wvu.edu/etd

Part of the Biology Commons

\section{Recommended Citation}

Shrewsberry, Darin Lee Jr, "Accessing the Functional Capabilities of the Tick Microbiome Through Metagenomics" (2020). Graduate Theses, Dissertations, and Problem Reports. 7687.

https://researchrepository.wvu.edu/etd/7687

This Thesis is protected by copyright and/or related rights. It has been brought to you by the The Research Repository @ WVU with permission from the rights-holder(s). You are free to use this Thesis in any way that is permitted by the copyright and related rights legislation that applies to your use. For other uses you must obtain permission from the rights-holder(s) directly, unless additional rights are indicated by a Creative Commons license in the record and/ or on the work itself. This Thesis has been accepted for inclusion in WVU Graduate Theses, Dissertations, and Problem Reports collection by an authorized administrator of The Research Repository @ WVU. For more information, please contact researchrepository@mail.wvu.edu. 

Through Metagenomics

Darin Lee Shrewsberry Jr

Follow this and additional works at: https://researchrepository.wvu.edu/etd

Part of the Biology Commons 
Accessing the Functional Capabilities of the Tick Microbiome Through Metagenomics

Darin L. Shrewsberry Jr.

Thesis submitted

to the Eberly College of Arts and Sciences

at West Virginia University

in partial fulfillment of the requirements for the degree of

Master of Science in

Biology

Timothy Driscoll, Ph.D., Chair

Rita Rio, Ph.D.

Craig Barrett, Ph.D.

Department of Biology

Morgantown, West Virginia

2020

Keywords: Tick, metagenome

Copyright 2020 Darin Shrewsberry 


\begin{abstract}
Accessing the Functional Capabilities of the Tick Microbiome Through Metagenomics
\end{abstract}

Darin Lee Shrewsberry Jr.

The black-legged tick Ixodes scapularis is a common ectoparasite of animals and an obligate blood feeder, attaching to a host animal and taking a blood meal once per life stage (i.e. 3 times during its life). Unfortunately for the tick, blood represents a nutrient poor diet largely consisting of lipids and proteins but notably lacking in essential nutrients such a B vitamins (e.g., biotin, riboflavin, niacin) Other exclusive blood feeders such as the tsetse fly harbor symbiotic bacteria that provision B-complex vitamins to their host. I. scapularis harbors Rickettsia buchneri an endoparasitic bacterium that intriguingly possesses two copies of a complete biotin synthesis operon; however, there is no evidence that $R$. buchneri is required for I. scapularis fitness, or that it provisions biotin to its host. Consequently, it remains an open question how I. scapularis and other ticks without endosymbionts thrive on nutrient-poor blood alone. In the current work, I present a method to isolate the tick microbiome away from host cells to interrogate the complete microbial metagenome for metabolic capabilities related to nutrient supplementation. This method will allow us to analyze the entire microbial metagenome of small arthropods such as ticks - previously inaccessible due to overwhelming amounts of host DNA - and enable characterization of host-microbiome metabolic interdependency, providing novel insight into microbial ecology within ticks and other hematophagous arthropods. 


\section{Acknowledgements}

First, I want to thank my research advisor, Dr. Timothy Driscoll, for agreeing to take me in to the lab as an undergraduate and sparking my interest in a whole new realm of biology and for taking me in as a graduate student a short time later. I have grown as a person and a researcher through my time in the lab and it would not have happened without you. I want to thank my lab mates for being there to share my excitement when an experiment went well and also encouraging me when something inevitably went wrong. Thank you to Dr. Rita Rio and Dr. Craig Barrett for agreeing to be a part of my committee. I appreciate all of the guidance and knowledge you have given me during my time here. Thank you to Dr. Victoria Verhoeve for helping fine tune my lab skills. I also must thank Dr. Katrina Stewart, Dr. Jen Hawkins, Dr. Jen Gallagher, and Cheryl Walton for helping me grow as an instructor. Thank you to the West Virginia University biology department as a whole for always focusing on the students first, fostering a positive environment, and making us all feel like one big family.

Finally, I thank my family and friends for the constant support over the years. Without you, I could not have accomplished this. 


\section{Contents}

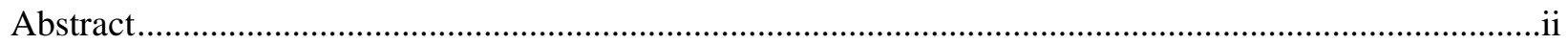

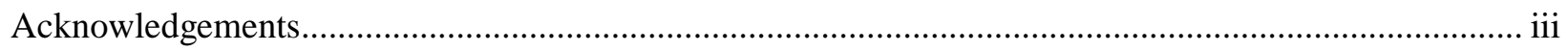

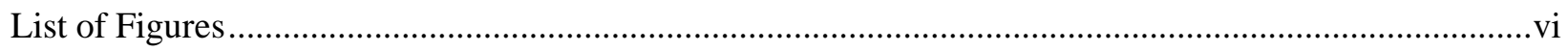

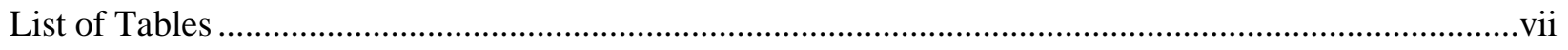

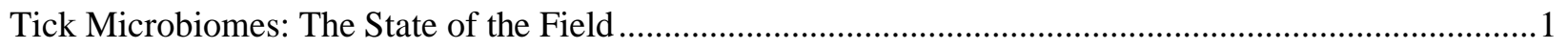

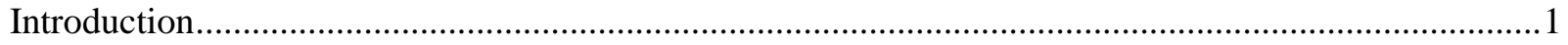

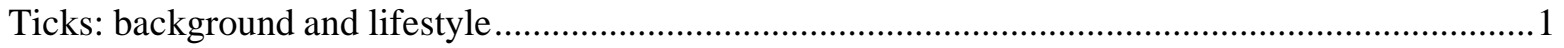

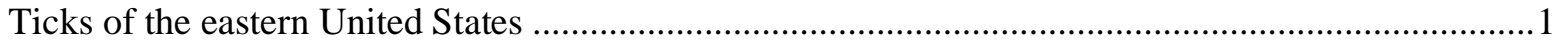

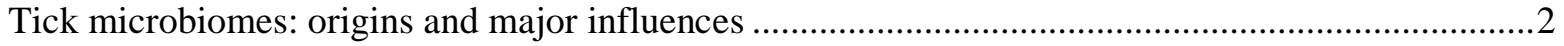

Tick microbiome composition and the role of generation sequencing ............................................

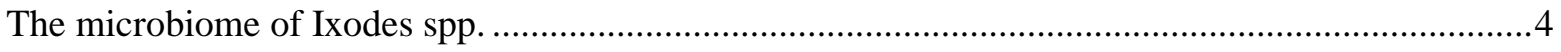

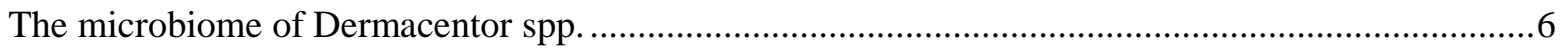

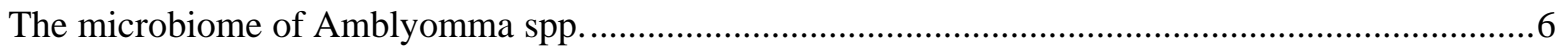

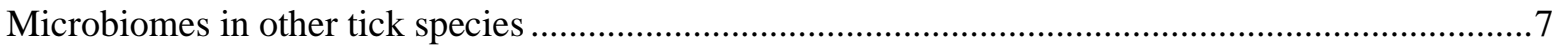

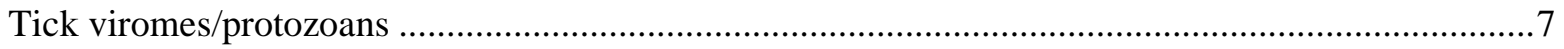

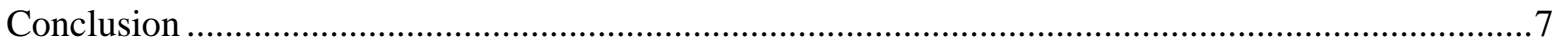

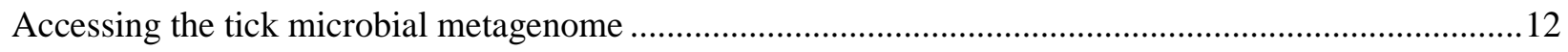

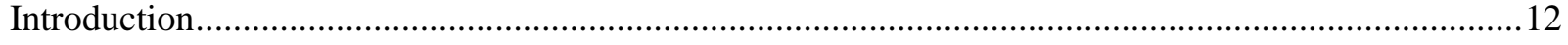

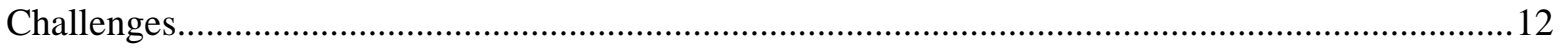

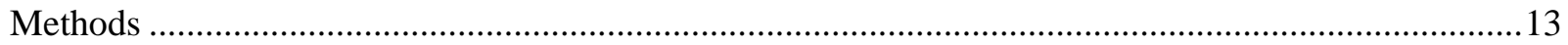

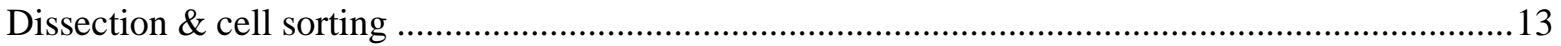

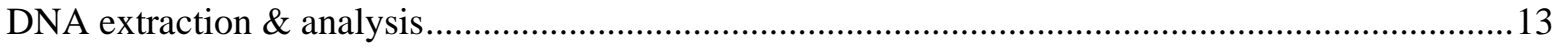

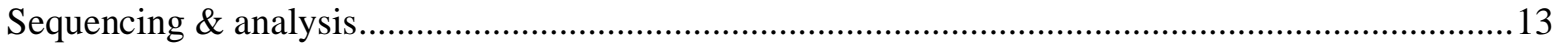

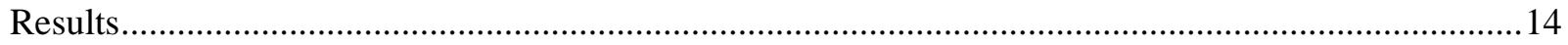

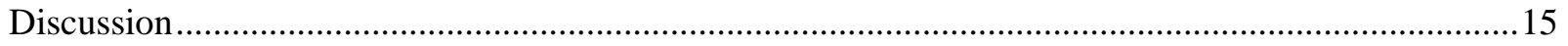

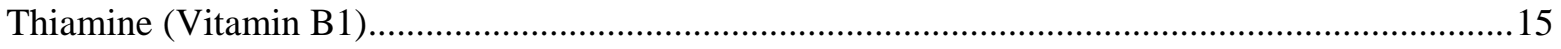

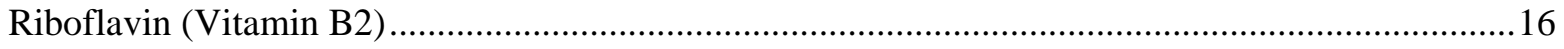

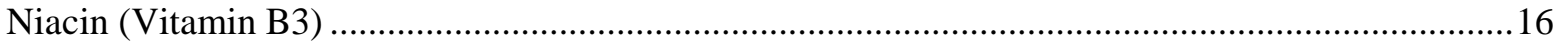

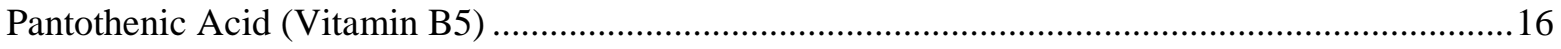

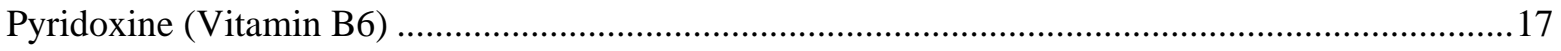

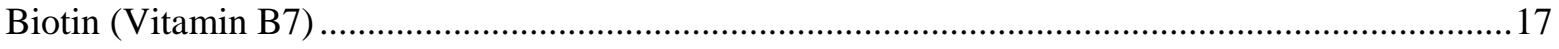

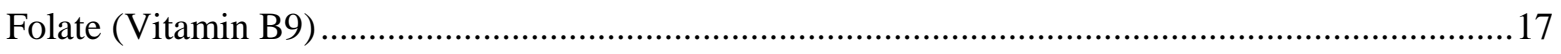


Cobalamin (Vitamin B12)

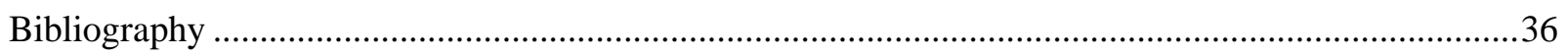




\section{List of Figures}

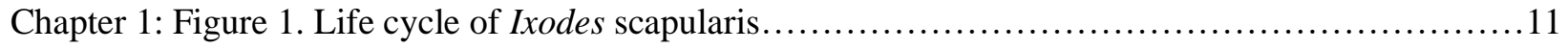

Chapter 2: Figure 1. Experimental design ................................................. 19

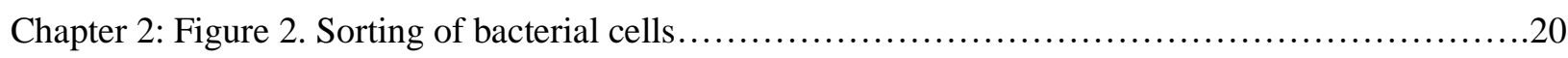

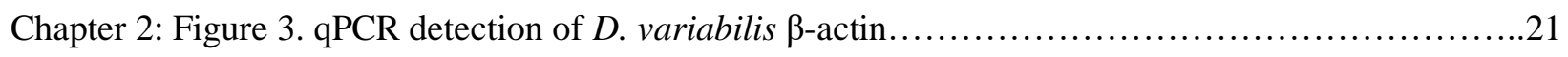

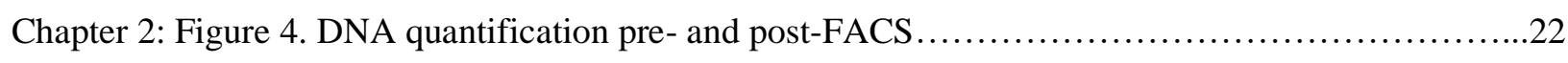

Chapter 2: Figure 5. PCR amplification of bacterial 16S pre- and post-FACS ......................23

Chapter 2: Figure 6. MG-RAST read annotation: domain level abundance..........................25

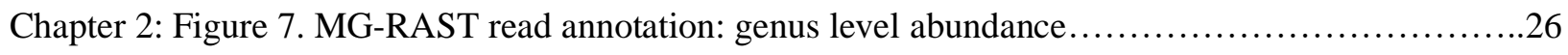

Chapter 2: Figure 8. MG-RAST read annotation: subsystem abundance............................27

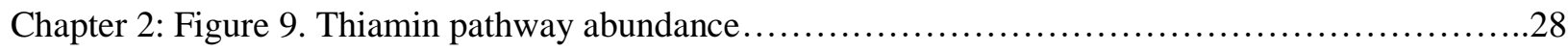

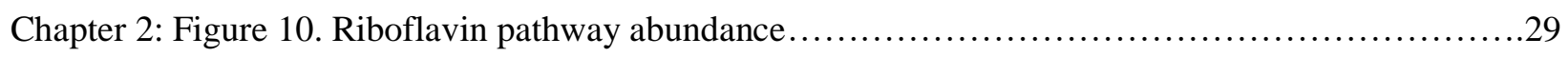

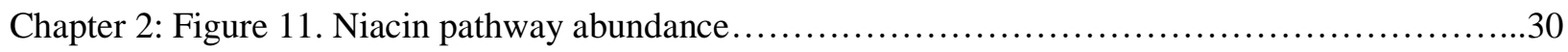

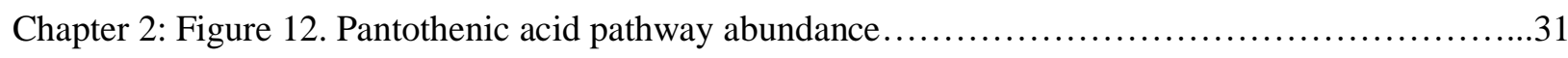

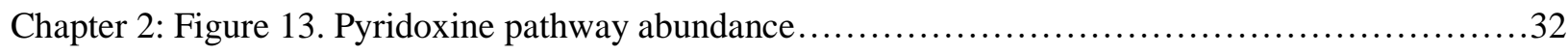

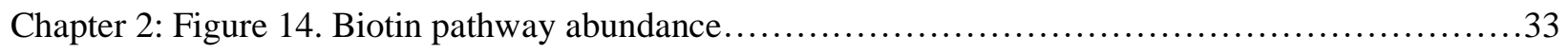

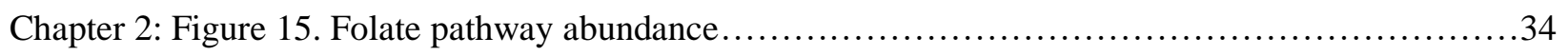

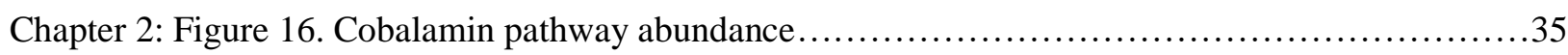

Chapter 2: Figure 17. Mean estimation of microbial cell counts..................................... 36 


\section{List of Tables}

Chapter 1: Table 1. Summary of microbiome studies in major tick species..........................8

Chapter 1: Table 2. Summary of genera identified in I. scapularis microbiome.........................9

Chapter 1: Table 3. Summary of genera identified in D. variabilis microbiome........................ 10

Chapter 2: Table 1. D. variabilis metagenome assembly statistics..................................24 


\section{Tick Microbiomes: The State of the Field}

\section{Introduction}

\section{Ticks: background and lifestyle}

Ticks (Order: Ixodida) are obligate sanguivorous ectoparasites composed of 3 families: Ixodidae (hard ticks, >700 species), Argasidae (soft ticks, > 200 species), and Nuttallielidae (1 species). At least 28 species transmit human pathogens across the globe and the list of pathogens known to be transmitted is increasing, in part, due to climate change (Anderson \& Magnarelli, 2008; Gray et al., 2009; Spolidorio et al., 2010). Ticks are introduced to microbial communities of bacteria, including both pathogens and nonpathogens, during feeding on varied hosts as well as during their extensive time off-host. Hard ticks range widely and feed on multiple different host species, whereas most soft ticks are restricted to a single host animal, usually inhabiting a burrow. Consequently, the feeding and lifestyle habits of different tick species suggest they will be colonized by highly variable microbial communities; it also points to differences in pathogen acquisition. Once a tick is infected with a pathogen, colonization is typically maintained throughout the lifespan of the tick, although some pathogens see a dramatic decrease in numbers during transstadial transmission (Soneshine, 1991). In some cases, bacteria can be transovarially transmitted to offspring where the infection is maintained (Soneshine, 1991).

A tick's life span is comprised of 3 life stages: larvae, nymph, and adult. Hard ticks (family Ixodidae) generally take one blood meal at each stage of development while soft ticks (family Argasidae) often feed multiple times (Anderson \& Magnarelli, 2008). Hard ticks are different in that they do not take bloodmeals from multiple hosts in the way that other arthropods such as mosquitoes do. Instead, once they have found a compliant host, such as a small mouse or a deer, they will attach and remain attached until they have fed to repletion. This process can take a few days up to several weeks and is in stark contrast to a mosquito, that takes a brief meal (lasting up to a few minutes) from one individual and leaves once feeding is complete. This feeding mechanism has led to an evolutionary pressure in ticks for mouthparts that are extremely specialized for attaching and remaining so through extended feeding. They have also evolved powerful analgesics that are excreted in their saliva to numb the site of attachment, in order to remain undetected while feeding, as well as blood thinners to aid in uptake of a meal (Chmelar et al., 2012).

\section{Ticks of the eastern United States}

Behind mosquitoes, ticks are responsible for the greatest level of vector-borne disease transmission on the planet (Herrmann et al., 2014). Ixodes scapularis (the Eastern black-legged tick) has a widespread and increasing geographical range in the Eastern US and harbors a myriad of human pathogens, including Borrelia burgdorferi (Lyme disease), Anaplasma phagocytophilum (human granulocytic anaplasmosis), and Powassan virus (Powassan virus encephalitis) (Eisen \& Eisen, 2018). In the US, $\sim 30,000$ cases of tick-borne Lyme disease cases are reported in the US every year -- with estimates suggesting 300,000 infections -- making it the most common tick-borne disease (TBD) in the nation. In addition to the health costs, Lyme disease is estimated to cost patients an average of $\$ 3,000$ in the US, with a total national economic burden of $\sim 3$ billion annually (Adrion et al., 2015).Other serious but less common TBDs include Anaplasmosis/Erhlichiosis (6,123 US cases in 2018), spotted fever Rickettsioses (5,544 cases), Babesiosis (2,160 cases), Tularemia (229 cases) and Powassan virus (21 cases); these are likewise responsible for hospitalizations as well as economic burden on patients due to treatment and potentially hours of work lost (Centers for Disease Control and Prevention, 
Among these (and other) human pathogens, I. scapularis also harbors non-pathogens as well. For example, various species of endosymbiotic bacteria have been described such as Rickettsia buchneri, which resides in the ovaries of I. scapularis and has recently been detected in the salivary glands (AlKhafaji et al., 2020; Kurtti et al., 2015). This bacterium is intriguing as it possesses two functional copies of the biotin (B7) synthesis operon located on a plasmid, pREIS2. This suggests the possibility of $R$. buchneri as a nutritional endosymbiont in I. scapularis (Gillespie et al., 2012).

Dermacentor variabilis (the American dog tick) is the most widely distributed tick in North America (Sonenshine DE, Roe RM. Biology of ticks. vol. 2. 2nd ed. New York: Oxford University Press; 2014.) It is responsible for the transmission of spotted fever group Rickettsia (SFGR), a group of bacteria that include the causative agents of Rocky Mountain Spotted Fever (RMSF) (R. rickettsii) and other rickettsioses, as well as Francisella tularensis (tularemia), Coxiella burnetii (Q Fever), and Anaplasma spp. (anaplasmosis in both humans and animals; de la Fuente et al., 2008). SFG Rickettsioses are particularly difficult to assess in terms of health and economic costs: they present with fairly nonspecific symptoms (fever, malaise, headache) making diagnosis difficult; they cover a wide spectrum of severity from mild to highly fatal; and they often resolve without requiring treatment or hospitalization. For example, RMSF is estimated to cost the state of Arizona \$13million/year although the authors believe this to be a significant underestimate (Drexler et al., 2015). Livestock also suffer from pathogens transmitted by $D$. variabilis; for example, bovine anaplasmosis is estimated to cost US farmers $\$ 300 \mathrm{million} /$ year (Aubry \& Geale, 2011).

Amblyomma americanum (Lone-Star tick) is another important vector of TBD in the US (Childs $\&$ Paddock, 2002). It is a known vector for Erhlichia chaffeensis (human monocytic ehrlichiosis) and $E$. ewingii (canine and human granulocytic erhlichioses), and is suspected to transmit Borrelia lonestari (Southern Tick-Associated Rash Illness or STARI) as well as the protozoan Theileria cervi (Ewing et al., 1995; Samuel \& Trainer, 1970; Varela et al., 2004). Recently, it has been reported that A. americanum is potentially responsible for alpha-gal allergies, IgE-mediated reactions against a carbohydrate found in mammalian meat, excluding primates (Jackson, 2018).

In addition to transmitting microbial pathogens, ticks (like all other eukaryotes) harbor diverse and varied microbial communities (microbiomes). These communities include vertically-inherited, longterm residents (e.g., R. buchneri, Rickettsia peacockii, Coxiella-like endosymbiont of A. americanum) as well as complex communities that inhabit tick midgut, ovarian, and salivary tissues. Microbiome studies from other systems strongly suggest that these communities have an important role to play in tick survival and fitness (Gillespie et al., 2012; Gurfield et al., 2017; Pachebat et al., 2013; Smith et al., 2015a; Snyder et al., 2010).

\section{Tick microbiomes: origins and major influences:}

The term "microbiome" was first coined by Joshua Lederberg as the communities of commensal, symbiotic, and pathogenic microorganisms that occupy various niches within our body (Hooper \& Gordon, 2001). While this was originally defined in the context of humans, the term broadly applies to any metazoan organism as they all rely on a consortium of microbes to survive. Arthropods (including ticks) do not stray from these requirements as essential microbes have been shown to influence tick life cycle, reproductive fitness, survival, and vectorial competence (Dennison et al., 2014; Weiss \& Aksoy, 2011; Zug \& Hammerstein, 2015).

The microbiome of the tick is important to the survival of the host, perhaps most notably as the members present can determine the host's susceptibility to pathogens or provision nutrients to supplement the nutrient-poor blood meal (Beard et al., 2002; Gall et al., 2016; Macaluso et al., 2002; Smith et al., 
2015a). Understanding the composition of I. scapularis and other tick microbiomes would provide the ability to pinpoint key members of the community that could be targets for vector control. Should an endosymbiont be identified, manipulating these could reduce infestations and lead to a decrease the prevalence of tick-borne infections (Greay et al., 2018).

In ticks, larvae acquire endosymbionts from their mother via transovarial transmission.

Additionally, it has been suggested that the maternal microbiota is the first to inoculate developing larvae (Narasimhan et al., 2014). It has also been suggested that paternally-transmitted microbes can be acquired through copulation, thus increasing microbiome diversity (Afzelius et al., 1989). The effect of the environment on the composition of tick microbiomes has been well-documented in comparisons between wild-caught ticks and those from laboratory colonies. For example, I. scapularis larvae hatched in sterile environments harbor a significantly different microbiome from their non-sterile counterparts (Narasimhan et al., 2014), indicating that the environment is involved in modulating the microbial diversity within ticks. Comparing the functional capabilities of microbiomes from laboratory reared ticks and wild-caught ticks will be valuable in characterizing the core microbiota conserved across individual ticks as well as allow for inference of the core functions of these microbiota within the tick.

Wild tick microbiomes are subject to a wide range of factors that can affect their composition such as tick species and sex, geographical location (particularly, the humidity and temperature of those locations), the host a bloodmeal was taken from, and even the physical location within the tick (Andreotti et al., 2011; Carpi et al., 2011; Gurfield et al., 2017; Qiu et al., 2014; Trout Fryxell \& DeBruyn, 2016; Van Treuren et al., 2015; Williams-Newkirk et al., 2014). It has also been shown that members of the microbiome can influence the composition of the community (Abraham et al., 2017; Gurfield et al., 2017). In mammals, diet plays a key role in shaping the microbiome (Carmody et al., 2015); likewise it is reasonable to posit that the strict blood diet of ticks selects for certain genera in the microbiome. Host genetics may also play a role in microbiome composition. In D. melanogaster, microbiome diversity is low despite the wide variety of meals available for the fly (Broderick \& Lemaitre, 2012). Conversely, ticks are restricted to a diet of blood but evince a more complex microbiome than flies (Narasimhan et al., 2014). This diversity may be associated with the host that is fed upon (Zhang et al., 2014). Genetic influence of the host on the microbial diversity within it is one possible explanation for this, as one would expect that ticks to show a similar microbiome composition across species if diet were the sole driver of microbial diversity. Combined, these factors present a challenge in uncovering the core microbial communities within ticks.

Interestingly, it was recently reported that I. scapularis does not harbor a stable microbial community (Ross et al., 2018). This study found that wild-caught ticks possessed a limited microbiota dominated by endosymbionts such as Rickettsia, which the author suggests is the primary driver of microbial abundance in I. scapularis. Between all samples tested, only six taxa were present in all: Rickettsia, Bacillus, Borrelia, Francisella, Escherichia, and Enterobacteriaceae. Those samples that did not show an abundance of Rickettsia were dominated by either Bacillus, Pseudomonas, or Enterobacteriaceae. Intriguingly, when species in these three groups dominated the microbiota, $B$. burgdorferi load was decreased suggesting that $B$. burgdorferi colonization is potentially inhibited by Bacillus, Psuedomonas, Enterobacteriaceae or a combination of them. (Ross et al., 2018). Similar patterns were also noted in five other tick species tested: (two Amblyomma spp., two Dermacentor spp., and Ixodes pacificus). Francisella and Rickettsia dominated abundance in two Amblyomma spp., Francisella was the most abundant in two Dermacentor spp., and Rickettsia was most prominent in Ixodes pacificus. 
Tick microbiome composition and the role of next-generation sequencing

Nucleic acids have been sequenced since 1965 starting with Robert Holley generating the first sequence from Saccharomyces cerevisiae (Holley et al., 1965). Various techniques had been utilized for nucleic acid sequencing, but in 1977 'first generation' sequencing had been born with the adoption of Maxim and Gilbert's technique utilizing radiolabeled DNA treated with chemicals that cause breaks in specific bases in the DNA chain and running those cleaved fragments on a polyacrylamide gel to infer the sequences (Maxam \& Gilbert, 1977). In 1977, Fred Sanger developed the chain-termination method which utilized both deoxyribonucleotides (dNTPs) and dideoxyribonucleotides (ddNTPs) that lacked the 3 ' hydroxyl group required for extension of DNA chains. Mixing radiolabeled ddNTPs into a reaction allowed for the generation of DNA strands of every possible length (Sanger et al., 1977). Pyrosequencing (eventually landing in the hands of 454 Life Sciences, then Roche) later became the first major 'nextgeneration sequencing' (NGS) technology. This technology allowed for mass parallelization of sequencing, which allowed for greater amounts of DNA to be sequenced in a single run. This method requires libraries of DNA molecules to be attached to beads (by way of adapter sequences) which then undergo water-in-oil emulsion PCR (emPCR) to coat beads in clonal DNA (Margulies et al., 2005). The sequences are then amplified in the emulsion droplets. However, 454 pyrosequencing was discontinued in 2013. Illumina sequencing rode on the heels of 454's success and quickly rose in popularity after the development of paired-end read generation. Having paired-end reads provides a greater amount of data and allows for greater accuracy in mapping reads to reference genomes, particularly across repetitive regions (Heather \& Chain, 2016). This was built on with the development of the HiSeq and MiSeq platforms which were capable of greater read length/depth and faster turnaround (but lower throughput) with greater read length, respectively. The success of Illumina is generally considered to be the greatest contribution of second-generation sequencing techniques (Balasubramanian, 2011; Quail et al., 2012)

Third-generation sequencing introduced single molecule sequencing (SMS) as well as real-time sequencing. SMS eliminated the requirement for DNA amplification, which was necessary for all previous sequencing techniques (Schadt et al., 2010). The first to do this was Stephen Quake and the technique was purchased by Helicos Biosciences. Helicos went bankrupt in 2012, however it was not long before another company took over (Heather \& Chain, 2016). Pacific Biosciences developed the single molecule real time (SMRT) technique which is utilized on their platforms. With PacBio sequencing platforms, reads exceeding $10 \mathrm{~kb}$ can be generated. This length is useful for bridging the gaps of highly repetitive regions that may otherwise hinder shorter red length sequencing platforms (van Dijk et al., 2014).

Next-Generation Sequencing is generally used to describe any high-throughput, massively parallel sequencing technology. NGS has enabled researchers to understand how the interactions between microbes influences the composition of the microbiome. Using NGS to identify the factors that influence microbiome composition may be crucial to the development of novel TBD control methods. Currently, acaricides and vaccines are the two most common strategies, but each presents challenges to future use. Tick populations that are resistant to acaricide treatments are becoming more common (de la Fuente \& Contreras, 2015). Vaccine development, while promising, requires a large up-front investment in money and time, sometimes up to ten years (de la Fuente \& Contreras, 2015). Alternative TBD control strategies could take shape in the form of manipulating the tick microbiome. Inoculating ticks with microbes that are capable of excluding or decreasing TBD pathogens would ultimately lead to a decrease in circulation of TBD as well as a long-term decrease in TBD cases. Similar strategies have been employed in arthropod vectors such as Culex pipiens and Aedes spp. using Wolbachia pipientis, which has been shown to inhibit dengue virus colonization (Jeffries \& Walker, 2016). Further research on the tick microbiome and the 
interactions between members will increase our understanding of the molecular basis of these interactions and inform ways that similar disease control methods can be employed in ticks.

Typically, studies on tick microbiomes have used NGS to sequence the PCR-amplified hypervariable regions of bacterial 16S rRNA, primarily from whole tick samples (Petrosino et al., 2009). This approach neatly sidesteps the considerable challenge posed by trying to isolate microbial DNA from a tick in enough purity and quantity to be sequenced. One limitation presented with the use of whole ticks is that it limits the ability to define tissue-specific microbiomes, including important information regarding the context of host-microbe and microbe-microbe interactions (Schabereiter-Gurtner et al., 2003). It is also more difficult to separate bona fide members of the community from those that are present on the exoskeleton which may be environmental contaminants. Although surface sterilization can help, when it is carried out, there is currently no widely-accepted standard treatment and the effectiveness is often unclear.

Despite the observed diversity, all tick species studied to date have shown common broad themes in the composition of their microbiomes (table 1). In order of occurrence, the following phyla predominate: Proteobacteria, Actinobacteria, Firmicutes, and Bacteroidetes. Phyla such as Acidobacteria, Cyanobacteria, Fusobacteria, and candidate phyla TM7 are also present, though in reduced abundance (Budachetri et al., 2014; Narasimhan et al., 2014). The most abundant bacterial species that are frequently identified include endosymbionts such as Coxiella spp, Rickettsia spp. Francisella spp., "Candidatus Midichloria mitochondrii" as well as assorted pathogenic, environmental, and vertebrate skin-associated bacteria (Andreotti et al., 2011; Hawlena et al., 2013) (summarized in Table 2).

The microbiome of Ixodes spp.

Two Ixodes species (I. scapularis and I. pacificus) are the major TBD vectors in the US (Piesman \& Eisen, 2008). In Europe, that title goes to I. ricinus (Sprong et al., 2018).Consequently, these species have received considerable amounts of attention regarding the microbial communities within them.

In I. scapularis, two microbiome studies were conducted using 454 pyrosequencing of dissected gut tissue (Narasimhan et al., 2014) and temporal temperature gradient gel electrophoresis of whole tick samples (Moreno et al., 2006). Despite the use of two different methodologies, it was concluded that four genera are typically present: Stenotrophomonas, Sphingobacterium, Pseudomonas, and Acinetobacter. The overlap of these genera between the two different methods corroborates the presence of these bacteria in the I. scapularis microbiome. The agreement between these two methodologies allows for the identification of exoskeleton-associated bacteria that are unlikely to be part of the internal microbiome. These genera, as well as Enterobacter are found across several hard tick species as well (Narasimhan \& Fikrig, 2015). In the ovaries, it was found that only bacteria closely related to SFGR were present, and PCR amplification only detected these bacteria in $\sim 50 \%$ of ticks indicating that the bacteria is cleared in males after molting from larvae to nymphs. Further testing of specific tissues confirmed this as only ovary samples yielded PCR amplification of SFGR (Noda et al., 1997). Interestingly, R. buchneri was detected in I. scapularis gut tissue and in $>50 \%$ of adult ticks (Hagen et al., 2018).

When the composition of the tick gut microbiota is altered via gentamicin treatment, the integrity of the peritrophic matrix (PM), a non-cellular matrix that separates the food from the midgut epithelium, in the tick gut is compromised. The PM prevents pathogens and indigenous gut bacteria from breaching the gut epithelium. The reduced integrity of the PM leads to a reduction in colonization of B. burgdorferi, as it shields $B$. burgdorferi from the blood-filled gut lumen(Narasimhan et al., 2014). This suggests that members of the microbiome are necessary, either directly or indirectly, for the colonization of $B$. burgdorferi in I. scapularis (Hawlena et al., 2013). It was also found that Rickettsia was always present. 
In addition, the human pathogen A. phagocytophilum induces transcription of an antifreeze glycoprotein (IAFGP) in I. scapularis, which leads to a decrease in Enterococcus and Rickettsia numbers and an increase in Pseudomonas counts. These results further support a crucial role for host-microbiome interactions in influencing pathogen success in I. scapularis (Abraham et al., 2017; Heisig et al., 2014).

Because of its medical importance in Europe, I. ricinus has been investigated frequently using 16S NGS platforms. Ticks acquired from regions endemic for Lyme disease were found to carry various pathogenic species within the Borrelia genera, including B. burgdorferi, Borrelia garinii and Borrelia afzelii as well as Anaplasma phagocytophilum, Rickettsia helvetica and "Candidatus Neoehrlichia mikurensis" (Almeida et al., 2012; Carpi et al., 2011; Gofton et al., 2015; Nakao et al., 2013; VayssierTaussat et al., 2013). In addition to pathogens, a potential endosymbiont "Candidatus Midichloria mitochondrii" was identified in $\sim 94 \%$ of field-collected females. The endosymbiont propagates in the tick oocytes and are transmitted transovarially to offspring, suggesting that it may play a role in fitness of the host (Beninati et al., 2004). Intriguingly, lab colonies of I. ricinus show a decreased level of "Candidatus Midichloria mitochondrii" indicating that the true advantage of the endosymbiont is likely to be better understood in a field setting (Lo et al., 2006). Surprisingly, humans bitten by I. ricinus have tested seropositive for the endosymbiont, which was subsequently discovered in the salivary glands of adult female ticks (Mariconti et al., 2012). Bacteria similar to "Candidatus Midichloria mitochondrii" have also been identified in Ixodes, Dermacentor, Amblyomma, and Rhipecephalus ticks (Epis et al., 2008), pointing to a fairly widespread distribution of this species.

I.ricinus and I. scapularis ticks have also been associated with Wolbachia, a pervasive endoparasite found in most arthropods on the planet (Benson et al., 2004; Hartelt et al., 2004). In addition, Arsenophonous-like endosymbionts have been identified in I. ricinus, and it is possible that these bacteria may manipulate the reproduction of their tick host in order to increase their long-term maintenance in natural populations (Nováková et al., 2009; Subramanian et al., 2012).

Finally, in 2011, a novel Rickettsial endosymbiont was characterized in I. pacificus (Rickettsial endosymbiont of Ixodes pacificus; REIP) (Phan et al., 2011). It possesses all of the genes necessary for folate synthesis, suggesting a potential role in provisioning this B-vitamin to its tick host; however, curing the tick of REIP has no obvious effect on host fitness (Hunter et al., 2015; Kurlovs et al., 2014). In addition, follow-on genomic analysis showed that key genes in the folate synthesis pathway of REIP were pseudogenized, leaving the ecological role of this species in question (Driscoll et al., 2017).

\section{The microbiome of Dermacentor spp.}

Some of the most abundant species detected in tick microbiomes include members of the genera Coxiella, Francisella, and Rickettsia in which species of all three have been identified as endosymbionts in other hard ticks (Ahantarig et al., 2013; Hawlena et al., 2013; Lalzar et al., 2012). Francisella phylotypes $1 \& 2$ are pervasive among $D$. variabilis populations, and Arsenophonous is also highly prevalent (Hawlena et al., 2013). The Francisella spp. present are similar to previously characterized endosymbionts, suggesting that they are stable members of the D. variabilis microbiome. Recently, an inverse relationship between Fransicella-like endosymbionts (FLEs) and SFGR pathogen abundance in D. occidentalis was reported, suggesting that FLEs may interfere with the colonization by SFGR (Gurfield et al., 2017). Similar inhibitory interactions occur in other tick microbiota. For example, populations of $D$. andersoni ticks from Western Montana also harbor SFGR called Rickettsia peacockii, which localizes within the tick oocytes. The presence of $R$. peacockii does not allow the closely-related human pathogen $R$. rickettsii to establish colonies (Childs \& Paddock, 2002; Niebylski et al., 1997). 
It was discovered that the microbiome of $D$. andersoni includes members such as those in the genus Acinetobacter that may impact reproductive fitness as well as susceptibility to environmental contaminants. Antibiotic treatment of $D$. andersoni ticks was associated with a $25 \%$ decrease in ticks surviving to adulthood compared to untreated populations. Antibiotic-treated ticks were also less competent at feeding and molting. The presence of Francisella and Arsenophonous-like bacteria in D. andersoni provides insight into the possibility that these members are endosymbionts (Dergousoff \& Chilton, 2010; Niebylski et al., 1997). Additionally, it was discovered that the microbiome composition fluctuated generationally, further adding to the complex story that is the tick microbiome (Clayton et al., 2015).

The microbiome of Amblyomma spp.

In 2006, a novel Coxiella species was discovered in A. americanum. Due to the ubiquitous presence in tick sample, the presence in eggs, and the appearance of a reduced genome, a common indicator of endosymbionts, researchers concluded that this novel species was likely an endosymbiont of the tick however, its importance could not yet be suggested (Jasinskas et al., 2007; Smith et al., 2015a). It was then found that curing the tick of their Coxiella endosymbionts reduced the fitness and survival of $A$. americanum. This result is due to the presence of complete or near complete B-complex biosynthesis pathways including thiamine (B1), riboflavin (B2), nicotinamide (B3), pantothenic acid (B5), pyridoxine (B6), biotin (B7), and folic acid (B9) indicating that this endosymbiont likely provides its host tick with some or all of these nutrients (Smith et al., 2015a; Zhong et al., 2007). Later, it was shown via fluorescence in situ hybridization and microscopy that these endosymbionts are present in the midgut, Malpighian tubules as well as bright signals from the salivary glands, and oocytes. Oocyte presence is consistent with vertical transmission of the bacterium as they are present in all A. americanum ticks. Their presence in the salivary glands give rise to the possibility that they are transmitted to animals when fed on by the tick; alternatively, it is also possible that they localize as a mechanism for inhibiting transmission or acquisition of pathogens such as E. chaffeensis (Klyachko et al., 2007).

Wolbachia is commonly associated with arthropods and filarial nematodes ( Zhang et al., 2011). Members of this genus have been found to be associated with I. ricinus and I. scapularis (Benson et al., 2004; Hartelt et al., 2004). A novel Wolbachia was detected in female A. americanum ticks with infection rates ranging from $3.5 \%$ to $25 \%$ and was not detected at any level in males. Presence at these low levels typically indicates a male-killing role (Zhang et al., 2011). Phylogenetic estimation placed this novel bacterium in supergroup F, typically observed in filarial nematodes, Osmia caeruescens, and the genus Mengenilla, making it the first time a member of this supergroup was detected in ticks (Gerth et al., 2014; Zhang et al., 2011).

\section{Microbiomes in other tick species}

Bacteria related to Coxiella burnetii (the causative agent of Q Fever) were found to reside in the ovaries of Ornithordoros moubata, Rhipicephalus sanguineus, and Heamaphysalis longicornis. O. moubata also harbored an endosymbiont closely related to Francisella tularensis (causative agent of tularemia) (Burgdorfer \& Owen, 1956); however, the impact on the host is not yet understood.

\section{Tick viromes/protozoans}

As for viruses, few shotgun sequencing studies (targeting viral cDNA) on the virome of ticks have been conducted, this neglected realm can potentially unveil novel viral species as was the case when a shotgun sequencing study on the microbiome of Rhipicephalus spp. revealed novel anellovirus and nairovirus species (Xia et al., 2015). In 2018, researchers performed NGS on the salivary glands of the eastern paralysis tick, I. holocyclus. They found evidence for a novel virus in the Iflaviridae family 
dubbed Ixodes holocyclus iflavirus (IhIV) where it has been discovered in tick populations in New South Wales, and Queensland, Australia (O'Brien et al., 2018). A study in I. scapularis, D. variabilis, and A. americanum expanded on the understanding of tick viromes as 24 putative novel viruses were discovered. Those frequently detected include members of the Bunyaviridae, Rhabdoviridae, and Chuviridae families. Those members included 8 Bunyavirales-like species, 7 being identified in I. scapularis samples. This study also highlighted the drastic differences in viral presence between tick species. An average of 4 viruses were detected in each I. scapularis pool while A. americanum pools rarely tested positive for more than one virus (Tokarz et al., 2018).

One major tick-borne virus is Powassan Encephalitis Virus. It was first recognized as a human pathogen in 1958, when a child in Powassan, Ontario died due to encephalitis (Donald M. McLean \& Donahue, 1959). It is the only member of the tick-borne encephalitis serological complex of flaviviruses in North America. It was first isolated in D. andersoni and has since been discovered in I. scapularis, $I$. cookeii, I. spinipalis, and I. marxi (McLean et al., 1964; McLean \& Larke, 1963; Telford III et al., 1997; Thomas et al., 1960). As of 2019, several studies have identified a variety of viruses across both soft and hard ticks. These viruses include, but are not limited to, Phleboviruses, Rhabdoviruses, Nairoviruses, Churiviruses, and Orthomyxoviridae (Vandegrift \& Kapoor, 2019).

Protozoans such as those in the genera Babesia and Theileria are harbored by some species of ticks (Jongejan \& Uilenberg, 2004); however, shotgun sequencing has been under-utilized in the discovery of protozoans in the tick microbiome (Greay et al., 2018).

Given the current understanding of tick microbiomes and the diversity among them, one question still lingers. What are the major players in the I. scapularis and D. variabilis microbiomes particularly regarding host diet supplementation? Amblyomma americanum as well as other obligate blood feeders such as Tseste flies and body lice are known to harbor bacteria that synthesize and provision B-complex vitamins to their host(Nikoh et al., 2014; Nogge, 1976; Smith et al., 2015b). Thus far, no member of the $I$. scapularis or $D$. variabilis microbiome has been confirmed to fill this role outside of one potential suspect in $R$. buchneri. In this, we hypothesize that the microbiomes of these two species contain members that are capable of synthesizing and provisioning one or multiple B-complex vitamins to supplement the nutrient poor blood diet of the hosts. Our novel approach to addressing this question aims to address this question. 
Table 1: Summary of microbiome studies in major tick species. Adapted from Narasimham \& Fikrig. 2015 and Greay et al. 2018.

\begin{tabular}{|c|c|c|c|c|c|c|}
\hline \multirow{2}{*}{$\begin{array}{l}\text { Locati } \\
\text { USA }\end{array}$} & Genus/Species & \multirow{2}{*}{$\frac{\text { Target }}{16 \mathrm{~S}}$} & \multirow{2}{*}{$\begin{array}{l}\text { Tissue Assessed } \\
\text { Whole Tick }\end{array}$} & Developmental Stage & Approach $=$ & \multirow{2}{*}{\begin{tabular}{|l} 
Reference \\
Hartelt 2004
\end{tabular}} \\
\hline & I. scapularis & & & Nymph & Sanger & \\
\hline & I. scapularis & $16 S$ & Whole Tick & Nymph/Adult & \multicolumn{2}{|c|}{ Sanger TGGE Moreno 2006} \\
\hline & I. scapularis & $16 S$ (V3-V4 & Whole/Midgut/Salivary & Larval & 454 & Zolnik 2016 \\
\hline & I. scapularis & $16 \mathrm{~S}(\mathrm{~V} 2)$ & Whole/Midgut & Larval/Nymph & 454 & Narasimham 2014 \\
\hline & I. scapularis & $16 S(V 4)$ & Midgut & Nymph & Miseq & Abraham 2017 \\
\hline & I. scapularis/I. affinis & $16 S(V 1-V 4)$ & Whole Tick & Adult & 454 & Van-Trueren 2015 \\
\hline & I. scapularis/D. variabilis/A. americanum & Viral cDNA & Whole Tick & Adult & Ion Torrent & Tokarz 2014 \\
\hline & I. scapularis/D. variabilis & $16 \mathrm{~S}$ (V1-V3) & Whole Tick & Larval/Nymph & 454 & Hawlena 2013 \\
\hline & I. scapularis/D. variabilis & $16 S(V 1-V 3)$ & Whole Tick & Larval/Nymph & 454 & Rynkiewicz 2015 \\
\hline & I. pacificus & $16 \mathrm{~S}$ & Whole Tick & Larval/Nymph/Adult & Miseq & Swei 2017 \\
\hline & D. occidentalis & $16 \mathrm{~S}(\mathrm{~V} 1-\mathrm{V} 4)$ & Whole Tick & Adult & Miseq & Gurfield 2017 \\
\hline & D. andersoni & $16 S(V 1-V 4)$ & Salivary/Midgut & Larval/Nymph/Adult & 454 & Clayton 2015 \\
\hline & D. andersoni & $16 S(V 1-V 3)$ & Salivary/Midgut & Male & PacBio & Gall 2016 \\
\hline & A. americanum & $16 \mathrm{~S}$ & Whole Tick & Egg/Larval/Adult & 454 & Clay 2008 \\
\hline & A. americanum & $16 S$ & Whole Tick & Nymph/Adult & Ion Torrent & Lalzar 2012 \\
\hline & A. americanum & $16 S$ (V3-V5) & Whole Tick & Nymph/Adult & 454 & Williams-Newkirk 2014 \\
\hline & A. americanum & $16 S\left(V_{1}-V_{3}\right)$ & Whole Tick & Nymph/Adult & 454 & Ponnusamy 2014 \\
\hline & A. americanum & $16 S(V 3-V 4)$ & Whole Tick & Female & Miseq & Smith 2015 \\
\hline & A. americanum & $16 \mathrm{~S}(\mathrm{~V} 1-\mathrm{V} 4)$ & Whole Tick & Adult & MiSeq & Trout-Fryxell 2016 \\
\hline & A. americanum & $16 \mathrm{~S}$ (V5) & Whole Tick & Nymps/Adult & Ion Torrent & Menchaca 2013 \\
\hline & A. maculatum & $16 S(V 1-V 3)$ & Salivary/Midgut/Saliva & Adult & 454 & Budachetri 2014 \\
\hline & A. maculatum & $16 S(V 4-V 6)$ & Salivary/Midgut & Adult & 454 & Budachetri 2015 \\
\hline & Amblyomma/Haemaphysalis & $16 S(V 1-V 3)$ & Whole Tick & Larval/Nymph & 454 & Budachetri 2017 \\
\hline & A. tuberculatum & $16 S(V 3-V 7)$ & Whole/midgut & Female & 454 & Budachetri 2016 \\
\hline & R. microplus & $16 S(V 1-V 3)$ & Whole/midgut/ovaries & Egg/Adult/Female & 454 & Andreotti 2011 \\
\hline Canada & I. scapularis/I. angustus & $16 \mathrm{~S}$ (V1-V9) & Whole Tick & Nymph/Female & Ion Torrent & Sperling 2017 \\
\hline \multirow[t]{4}{*}{ China } & I. persulcatus & $16 S$ & Fed \& Unfed Whole & Adult & Illumina & Heise 2010 \\
\hline & I. persulcatus & $16 \mathrm{~S}(\mathrm{~V} 4)$ & Whole Tick & Adult & Miseq & Zhang 2014 \\
\hline & Rhipicephalus & Viral cDNA & Whole Tick & Adult & Ion Torrent & Xia 2015 \\
\hline & Dermacentor/Haemaphysalis/Hyalomma/Rhipicephalus/Argas & Viral cDNA & Whole Tick & Larval/Nymph/Adult & HiSeq & Li 2015 \& Shi 2016 \\
\hline \multirow[t]{2}{*}{ Australia } & Ixodes/amblyomma/Haemaphysalis & $16 \mathrm{~S}(\mathrm{~V} 1-\mathrm{V} 2)$ & Whole Tick & Nymph/Adult & Miseq & Gofton 2015 \\
\hline & I. holocyclus/I. ricinus & $16 \mathrm{~S}(\mathrm{~V} 1-\mathrm{V} 2)$ & Whole Tick & Nymph/Adult & Ion Torrent & Gofton \& Oksam 2015 \\
\hline \multirow[t]{2}{*}{ Japan } & Amblyomma/Ixodes/Haemaphysalis & \multicolumn{2}{|c|}{ Whole Genor Whole Tick } & Nymph/Adult & 454 & Nakao 2013 \\
\hline & ixodes/haemaphysalis & $16 \mathrm{~S}$ & Salivary & Adult & 454 & Qiu 2014 \\
\hline France & I. ricinus & \multicolumn{2}{|c|}{ Bacterial cDN/Whole Tick } & Nymph & HiSeq & Vayssier-Taussat 2013 \\
\hline
\end{tabular}


Table 2: Summary of bacterial and viral genera detected in Ixodes scapularis. Sources were obtained from a Pubmed search using the terms "microbiome of Ixodes scapularis" and manually assessing for relevance.

\begin{tabular}{|c|c|}
\hline Known Genera Present & Citation \\
\hline Rickettsia & \multirow{16}{*}{ Moreno et al. 2006} \\
\hline Anaplasma & \\
\hline Alfia & \\
\hline Ralstonia & \\
\hline Enterobacter & \\
\hline Photorabdus & \\
\hline Raoultella & \\
\hline Shigella & \\
\hline Acinetobacter & \\
\hline Pseudomonas & \\
\hline Stenotrophomonas & \\
\hline Rhodococcus & \\
\hline Williamsia & \\
\hline Borrelia & \\
\hline Sphingobacterium & \\
\hline Corynebacterium & \\
\hline Geobacillus & \multirow{15}{*}{ Narasimhan et al. 2014} \\
\hline Simplicispira & \\
\hline Diaphorobacter & \\
\hline Massilia & \\
\hline Streptococcus & \\
\hline Staphylococcus & \\
\hline Brevundimonas & \\
\hline Brevibacterium & \\
\hline Flavobacterium & \\
\hline Acidovorax & \\
\hline Aquabacterium & \\
\hline Delftia & \\
\hline Comamonas & \\
\hline Thioclava & \\
\hline Flaviviridae & \\
\hline Bunyavirales (nairovirus-like) & \multirow{8}{*}{ Tokarz et al. 2018} \\
\hline Bunyavirales (phlebovirus-like) & \\
\hline Bunyavirales & \\
\hline Chuviridae & \\
\hline Partitiviridae & \\
\hline Circoviridae & \\
\hline Picornaviralse & \\
\hline Rhabdoviridae & \\
\hline
\end{tabular}


Table 3: Summary of detected bacterial and viral genera in Dermacentor variabilis. Sources were obtained from a Pubmed search using the terms "microbiome of Dermacentor variabilis" and manually assessing for relevance.

\begin{tabular}{|l|c|}
\hline Known Genera Present & Citation \\
\hline Francisella & Hawlena et al. 2013 \\
\hline Arsenophonus & \\
\hline $\begin{array}{l}\text { Sphingomonas } \\
\text { Delftia }\end{array}$ & Travanty et al. 2019 \\
\hline Hymenobacter & \\
\hline Bunyaviridae (phlebovirus-like) & Tokarz et al. 2019 \\
\hline Rhabdoviridae & Chicana et al. 2019 \\
\hline Methylobacterium & \\
\hline
\end{tabular}




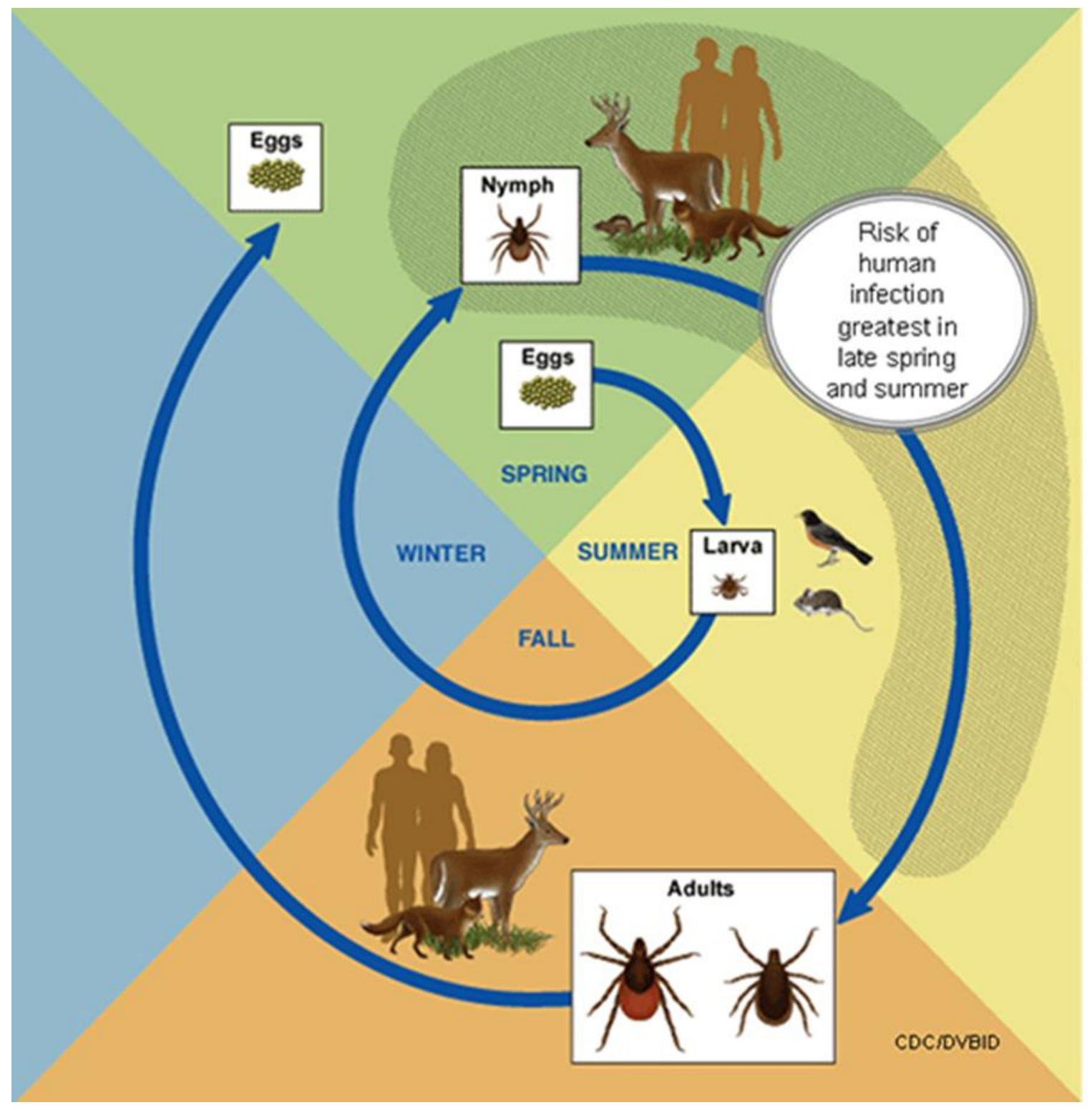

Figure 1: Life cycle of Ixodes scapularis. (Credit: CDC.gov) 


\section{Accessing the tick microbial metagenome}

\section{Introduction}

Ticks are major vectors for disease across the globe. Understanding the complex interactions between ticks and their harbored microorganisms specifically regarding pathogen acquisition and transmission, and B-complex vitamin biosynthesis and provisioning will enable researchers to identify targets for TBD control potentially by modifying the microbiome composition to prevent acquisition of a pathogen or by restricting the colonization of the symbionts that provide nutrients to supplement the nutrient poor diet of blood. Little is understood regarding nutrient acquisition in I. scapularis or $D$. variabilis outside of two possible endosymbionts, R. buchneri in I. scapularis and a Francisella-like member of the $D$. variabilis microbiome, however it is not well understood how these bacteria are affecting the survival of these ticks.

\section{Challenges}

The two most common ways to sequence the microbiome include amplicon sequencing (such as 16s rRNA studies) and shotgun sequencing (such as metagenomics and transcriptomics) (Smith et al., 2015b). Next-generation sequencing (NGS) has expanded researchers' abilities to sequence the genomes of single cells as well as further explore the members in a host's microbial community. The first use of NGS (via 454 pyrosequencing) in a tick microbiome was performed on Rhipicephalus (Boophilus) microplus where bacteria in the genera Wolbachia, Coxiella, and Borrelia were identified as well as multiple Staphylococcus species (Andreotti et al., 2011). In fact, most microbiome studies rely on amplicon sequencing with many of them using the Roche 454 platform to target the V1-V4 regions of $16 \mathrm{~s}$ rRNA. This platform is advantageous given its ability to generate long reads (up to $1 \mathrm{~kb}$ ) whereas Illumina's MiSeq and Thermofisher's Ion Torrent are capable of generating up to 50million reads of up to 600bp (single-end; 300bp paired-end) and 20 million 400bp single-end reads respectively. However, Roche discontinued their 454 platforms in 2013 and existing platforms lost support in 2016.

The consequence of utilizing $16 \mathrm{~S}$ amplicon sequencing is that it is generally unable to identify bacteria at greater than genus level. It is also unable to inform us about the function of the bacteria within the host. To address this challenge, we opted for whole metagenome sequencing of the tick microbiome.

One major obstacle in microbial metagenome sequencing is efficiently purifying the microbiome from the host. This leads to inefficient sequencing as many of the sequences will end up originating from the host, dominating the microbial sequences that are of real interest in these studies. This causes an increase in cost as one would need more sequencing runs to account for the underrepresented microbial sequences. We address this challenge by utilizing flow cytometry to separate cells based on size and fluorescent markers to exclude host cells and retain microbial cells.

Here, we have developed a novel method utilizing Fluorescence-Activated Cell Sorting for the purification of microbial cells from their tick host and efficiently sequence the microbial metagenome to uncover the composition of the microbial community within the midgut of the tick. Through this method, we are able to estimate the microbial cell load, as well as identify potential endosymbionts that are able to provide key nutrients such as B-complex vitamins to supplement the host bloodmeal or exclude TBDs by synthesis of antibiotic proteins to directly kill the TBD pathogen. 


\section{Methods}

Dissection \& cell sorting

Adult male and female I. scapularis and D. variabilis were acquired from the Oklahoma State University tick rearing facility. Tick midguts from each species ( $\mathrm{n}=5$ per sex) were dissected and placed into three pools. To prepare for Fluorescence Activated Cell Sorting (FACS), the tissues were digested by adding Fetal Bovine Serum at a 5\% concentration along with collagenase D $(3 \mathrm{mg} / \mathrm{ml})$, hyaluronidase $(1.5 \mathrm{mg} / \mathrm{ml})$ and DNase $\mathrm{I}(0.2 \mathrm{mg} / \mathrm{ml})$. The digests were incubated for 1 hour at $37^{\circ} \mathrm{C}$, then passed through a 70-micron filter, centrifuged at 4000 RPM for 10 minutes, and the pellets washed twice with $0.85 \%$ $\mathrm{NaCl}$ and each cell sample was suspended in a final volume of $1 \mathrm{~mL} 0.85 \% \mathrm{NaCl}$. Preparations were stained with SYTO-9 and Propidium Iodide (PI) and diluted 1:100 with $0.85 \% \mathrm{NaCl}$ prior to being sorted. SYTO-9-positive cells $<5$ microns in size were isolated via FACSAria III machine at the West Virginia University Flow Cytometry \& Single Cell Core Facility. Control samples included SYTO-9 only, PI only, and an unstained sample. 1 million microbial cells per sample was estimated to obtain the target 5ng of DNA to be used for sequencing. This estimation was made by multiplying the known range of bacterial genome sizes (112kbp,130kbp-14Mbp) (Bennett \& Moran, 2013; Han et al., 2013; McCutcheon \& Moran, 2012) by the weight of a DNA base (650 daltons) giving a bacterial genome weight range of .1 femtograms to 0.01 picograms and a range of 331,125 - 41,356,493 cells assuming 1 genome per microbial cell, $\sim 50 \%$ GC content, and an average genome length of $5 \mathrm{Mb}$, higher than that of the reported average of $\sim 3.8 \mathrm{Mb}$ (diCenzo \& Finan, 2017).

DNA extraction \& analysis

Sorted cells were centrifuged at $(16,000 \mathrm{x}$ g) for 20 minutes to pellet the cells. The supernatant fluid was discarded, and the pellets were resuspended in distilled water and placed in a microcentrifuge tube. DNA extraction was performed using the Arcturus PicoPure DNA extraction kit. 50ul of Proteinase

$\mathrm{K}$ was added to each cell sample and incubated for 1 hour at $60^{\circ} \mathrm{C}$ followed by a 5 -minute deactivation of proteinase $\mathrm{K}$ at $90^{\circ} \mathrm{C}$.

DNA concentration was measured using the dsDNA High Sensitivity assay on the QUBIT 3.0 platform. qPCR was performed to detect I. scapularis and D. variabilis B-actin levels pre/post FACS while $16 \mathrm{~S}$ was detected using traditional PCR and $1.5 \%$ agarose gel electrophoresis. qPCR reaction total volume was $25 \mu \mathrm{l}(12.5 \mu \mathrm{l}$ of Universal SYBR green supermix, $1 \mu \mathrm{l}$ of forward primer, $1 \mu \mathrm{l}$ of reverse primer, $1 \mu \mathrm{l}$ of DNA, and $9.5 \mu \mathrm{l}$ of PCR grade water). Conditions were denaturation for 2 minutes @ $95^{\circ} \mathrm{C}$, 40 cycles of 15 second denaturation @ $95^{\circ} \mathrm{C}$ and annealing/extension for 15 seconds @ $60^{\circ} \mathrm{C}$ followed by a melt curve starting @ $65^{\circ} \mathrm{C}$ for 5 seconds increasing to $95^{\circ} \mathrm{C}$ for 5 seconds. Traditional PCR conditions were $95^{\circ} \mathrm{C}$ for 10 minutes, 30 cycles of denaturation @ $95^{\circ} \mathrm{C}$ for 30 seconds, annealing @ $60^{\circ} \mathrm{C}$ for 30 seconds, and extension @ $72^{\circ} \mathrm{C}$ for 30 seconds), and a final extension @ $72^{\circ} \mathrm{C}$ for 5 minutes. Primers sequences are as follows; 16S Primers (5'-CCTACGGGNGGCWGCAG-3'-f; 5' -

GACTACHVGGGTATCTAATCC-3'-r), I. scapularis B-actin (5'-GGTATCGTGCTCGACTC-3'-f; 5'ATCAGGTAGTCGGTCAGG-3'-r) D. variabilis B-actin (5'-CTTTGTTTTCCCGAGCAGAG-3'-f; 5'CCAGGGCAGTAGAAGACGAG-3'-r)

\section{Sequencing \& analysis}

Sequencing was performed by the West Virginia University Genomics Core Facility. Paired-end 150 sequencing was performed via Illumina MiSeq platform. Sequences were quality checked using FastQC and trimmed/clipped accordingly using Trimmomatic (Bolger et al. 2014). SPAdes metagenome assembler was chosen for metagenome assembly. The assembly was quality checked using QUAST (Gurevich et al., 2013). Finally, the assembled genomes were uploaded to MG-RAST for annotation (Meyer et al., 2008).Contigs of interest were uploaded to BLAST for species level identification. 


\section{Results}

In total we obtained three pools ( $\mathrm{n}=5$ ticks per pool) of adult female $D$. variabilis and three pools ( $\mathrm{n}=5$ ticks per pool) of adult male gut samples.

qPCR detection of $D$. variabilis beta-actin shows a substantial decrease in the sample after FACS compared to pre-FACS, decreasing from $>19,000$ copies/ $\mu 1$ to $<1$ copy/ $\mu 1$ (Fig. 3) 16S rRNA amplification shows a retention of bacterial DNA in the post-FACS samples: DNA quantification shows a retention of $0.454 \mathrm{ng} / \mu \mathrm{l}$ of DNA a drastic decrease from the pre-FACS measurement of $13.9 \mathrm{ng} / \mu \mathrm{l}$ (Fig. 4). Traditional PCR amplification of bacterial 16S shows retention after FACS (Fig 5).

QUAST analysis of the SPAdes assembled metagenome shows $68.6 \mathrm{Mb}$ in 164,531 assembled contigs. The largest contig was $\sim 300 \mathrm{~kb}$ while the N50 was $8.4 \mathrm{~kb}$ (Table 1). MG-RAST annotation shows that $86.97 \%$ of the annotated contigs from the metagenome assembly of $D$. variabilis were of bacterial origin, $12.87 \%$ were of eukaryotic origin, $0.13 \%$ were viral, and the remaining sequences were either Archaeal or unclassified (Fig. 6).

Genus level annotation of the bacterial contigs show that $27.44 \%$ were identified as Bradyrhizobium spp. The next annotations show Pseudomonas (14.95\%), Propionibacterium (13.10\%), Mycobacterium (5.83\%) Ralstonia (4.84\%) Acidovorax (3.97\%) and Acinetobacter (1.11\%) (fig. 4) Members of the Francisella genus were also present in $\sim 74 \mathrm{~kb}$ of sequences in 200 contigs, or roughly $0.18 \%$ of the total microbial metagenome (Fig. 7). These members are expected members as Francisellalike bacteria have been identified in D. variabilis. Taxonomic richness calculated in MG-RAST of the metagenome is 92 species.

Top 5 hits of subsystem annotation show carbohydrates (12.43\%); amino acids and derivatives ( $10.91 \%)$; cofactors, vitamins, prosthetic groups, and pigments (6.54\%); and protein metabolism (5.23\%) as the most prominent functions in the assembly (Fig. 8). Of those, we chose to further analyze the cofactors, vitamins, prosthetic groups, and pigments subsystem as this group would contain gene annotations for B-complex vitamin biosynthesis.

Biotin (vitamin B7) biosynthesis genes were identified in the D. variabilis metagenome. 6 copies of bioC were identified as well as 1 copy of $b i o H, 7$ copies of biof, 18 copies of bioA, 7 copies of bioD, 6 copies of bioB and 3 copies of bioW divided among multiple bacterial genera, including Bradyrhizobium, Acinetobacter, Acidovorax, Pseudomonas, and Ralstonia. Genes for the biosynthesis of the remaining Bcomplex vitamins were detected as well. 135 copies of 10 thiamin biosynthesis genes, 92 copies of 13 niacin genes, 63 copies of 5 pyridoxine genes, 42 copies of 13 cobalamin genes, 38 copies of 5 folate genes, 23 copies of 2 pantothenic acid genes, and 19 copies of 2 riboflavin genes were identified in the $D$. variabilis metagenome (Figs. 9-16). These genes were identified as members of the genera Bradyrhizobium, Pseudomonas, Acidovorax, Stenotrophomonas, Cutibacterium, Francisella, Sphingobacterium, Acinetobacter, and Ralstonia.

Metagenome sequencing for I. scapularis was not possible due to a low DNA yield.

To estimate a cell count target to be obtained from each pool of ticks, assumptions of an average genome length of $5 \mathrm{Mb}, \sim 50 \% \mathrm{GC}$ content, and 1 genome per cell were made. Sorting of the full samples was not performed due to time constraints and cost. The average recovered cells from each 5-tick pool was 816,781 and 1,007,323 for female and male I. scapularis and 1,539,405 and 1,504,343 for female and male $D$. variabilis. This average was then used to calculate the average microbial cells obtained per pool and tick. These numbers were then used to estimate the total microbial load in each tick by factoring in the 1:100 dilution of samples prior to FACS being performed. Based on these estimations, a 2-Way 
ANOVA was performed using the AOV function in R with two factors, sex and species. Estimated microbial load was significantly different between I. scapularis and D. variabilis $(\mathrm{p}=0.000291)$ while there was no significant difference in estimated microbial cell load between sexes $(\mathrm{p}=0.459517)$ or the combination of species and sex $(\mathrm{p}=0.292236)$. (Fig. 17)

\section{Discussion}

To uncover the functional capabilities of the tick microbiome, a method to extract and purify the microbiome from the host was developed. With this method, host DNA was drastically decreased to $\sim 12 \%$ of the metagenome composition. Functionally, microbial genes were identified in every B-vitamin complex pathway. Multiple copies of biotin biosynthesis genes were identified; however, only 1 copy of bioH was annotated in the metagenome. Several factors may be responsible for this finding; First, bioH is often lost in biotin-synthesizing bacteria; however, many bacteria have evolved alternative methods that accomodate the absence of bioH such as bioU in E. chaffeensis (Hang et al., 2019). Second, bioU was not identified in the metagenome, but it is possible that alternate pathways for biotin biosynthesis exist but have not yet been discovered. Third, an apparent lack of bioH may arise from annotation errors in MGRAST. Uploaded sequences are clustered using an algorithm. Each of these clusters is considered a subsystem in MG-RAST. These subsystems are annotated based on similarities to sequences already present in the MG-RAST system. The sequence diversity in bioH as well as the aforementioned alternative strategies that exist for generating pimeloyl-CoA, may lead to suboptimal clustering in MGRAST therefore an inability to discover bioH in the metagenome.

The identification of multiple genes across the B-complex vitamin biosynthesis pathways is the first step in identifying novel endosymbionts and characterizing the host-endosymbiont relationship in ticks where the mechanisms are not well understood. Such is the case with I. scapularis and D. variabilis outside of their respective Rickettsia and Francisella endosymbionts whose role in nutrient provisioning has not yet been determine. While direct function of the bacteria that possess the genes for B-complex vitamin biosynthesis was not studied, their identification enables a specific targeting of those members to further study their impact on host fitness.

\section{Thiamine (Vitamin B1)}

135 copies of 10 thiamine biosynthesis genes were identified in the D. variabilis metagenome. Interestingly, one copy of thiL that is identified in the metagenome was identified to be that of Arsenophonous nasoniae, a bacterium that resides in the parasitic wasp Nasonia vitripennis and is known to synthesize thiamine as well as other B-complex vitamins (Darby et al., 2010). However, this Arsenophonous, if present, is potentially a relative of this bacterium as Arsenophonous-like bacteria have been identified in $D$. variabilis or the presence is due to a horizontal transfer event (Dergousoff \& Chilton, 2010).

Members of the genus Arsenophonous are also capable of synthesizing thiamine. Three Arsenophonous species present in whiteflies (Aleurodicus dispersus, ARAD; A. floccissimus, ARAF; and Trialeurodes vaporariorum, ARTV) were sequenced and their functional capabilities were compared (Santos-Garcia et al., 2018). ARAD possesses a complete thiamine pathway with the exception of $t h i H$; however, it was posited that a host-encoded gene may be capable of replacing the function of this missing gene. In contrast, ARTV was missing most of the thiamine biosynthesis pathway and appears incapable of de novo thiamine synthesis. 
Thiamine is known to be synthesized by Wigglesworthia glossinidia, a nutritional endosymbiont of the tsetse fly, Glossina morsitans (Akman et al., 2002). Wigglesworthia, has a highly reduced genome of $\sim 700 \mathrm{~kb}$ in size, and has lost a significant number of core metabolic functions; however, it has retained the complete pathways for thiamine (B1) pyridoxine (B6), and folate (B9) biosynthesis (Rio et al., 2012). Antibiotic elimination of Wigglesworthia from the tseste results in a loss of fecundity in the fly, as earlystage larva are aborted, while supplementation of the tsetse diet leads to a recovery in deficient females, supporting a role for Wigglesworthia in nutritional supplementation. Rhodococcus rhodnii, an endosymbiont of the Chagas disease vector, Rhodnius prolixus (reduviid bug), is able to synthesize thiamine and retains genes for 7 remaining b-complex vitamins. Reduviid bugs that lack this bacterium die prematurely, however the mechanism by which $R$. rhodnii provisions nutrients is not well understood as it could be a result of the host digesting the symbiont or the symbiont directly functions to supplement the host diet (Pachebat et al., 2013).

\section{Riboflavin (Vitamin B2)}

19 copies of 2 riboflavin genes ribA (11 copies) and ribE (8 copies) were annotated in the $D$. variabilis metagenome. The common bed bug, Cimex lectularis, harbors a Wolbachia endosymbiont $(w \mathrm{Cle})$ whose genome encodes a complete riboflavin synthesis pathway(Hosokawa et al., 2010a). Elimination of $w$ Cle from the bed bug results in decreased fitness of the host, suggesting it is providing riboflavin to the host (Moriyama et al. 2015). Interestingly, all insect-associated Wolbachia appear to retain the ability to synthesize riboflavin (Nikoh et al., 2014).

\section{Niacin (Vitamin B3)}

92 copies of 13 niacin pathway genes were detected in the metagenome of $D$. variabilis. The Sodalis present in the seal louse possesses a partial niacin synthesis pathway, and it is not clear whether the host was able to complement this pathway or if annotation error accounted for the missing piece of the pathway (Boyd et al., 2016). Other bacteria capable of synthesizing niacin include $R$. rhodnii (as discussed) as well as Bacteroides fragilis, Prevotellai copri, Ruminococcus lactaris, Clostridium dificile, Bifidobacterium infantis, Helicobacter pylori, and Fusobacterium varium (Deguchi et al., 1985; Said, 2011). Members of all these genera (excluding Rhodococcus) were identified in the $D$. variabilis metagenome.

\section{Pantothenic Acid (Vitamin B5)}

23 copies of two pantothenic acid synthesis genes were identified in the $D$. variabilis metagenome. In the human gut microbiome, B. fragilis, P. copri, Ruminococcus lactaris, Ruminococcus torques, and Salmonella enterica have been shown to encode complete pantothenic acid biosynthesis pathways (Magnúsdóttir et al., 2015). The human body louse Pediculus humanus humanus harbors a primary endosymbiont ("Candidatus Riesia pediculicola") that also possesses a complete pathway. When cleared from the host, nymphs perish during their first molt indicating that "Candidatus Riesia pediculicola" is necessary for survival of the host louse and suggesting it relies on pantothenate generated by its endosymbiont (Kirkness et al., 2010; Sasaki-Fukatsu et al., 2006). Finally, R. rhodnii in the reduviid bug also possesses genes required for the synthesis of pantothenic acid (Pachebat et al., 2013).

\section{Pyridoxine (Vitamin B6)}

63 copies of 5 pyridoxine synthesis genes were identified in the $D$. variabilis metagenome. In the human gut microbiome, B. fragilis, P. copri, Bifidobacterium longum, Collinsella aerofaciens, and $H$. pylori are known to synthesize vitamin B6 (Deguchi et al., 1985; Magnúsdóttir et al., 2015). In tsetse flies, Wigglesworthia provides vitamin B6 to the host, and absence of Wigglesworthia results in lower levels of circulating B6 in host hemolymph (as well as reduced levels of proline). This results in increased larval abortion in female flies (Michalkova et al., 2014). $R$. rhodnii in reduviid bugs also possesses the 
genes necessary for B6 synthesis (Pachebat et al., 2013). In A. americanum, a Coxiella-like endosymbiont (CLEAA) synthesizes and provisions B6 to supplement its host diet (Smith et al., 2015a; Zhong et al., 2007).

\section{Biotin (Vitamin B7)}

48 copies of 7 biotin synthesis genes were identified in the $D$. variabilis metagenome. 6 copies of bio $C$ were identified as well as 1 copy of bioH, 7 copies of bioF, 18 copies of bioA, 7 copies of bioD, 6 copies of bioB as well as 3 copies of bioW. In the human gut microbiota, a majority of Bacteroidetes, Fusobacteria, and Proteobacteria possess necessary genes for the synthesis of vitamin B7 (Magnúsdóttir et al., 2015). In arthropods, $R$. rhodnii (reduviid bugs), Wolbachia wCle (Cimex lectularis), and Coxiella (A. americanum \& $R$. turanicus) have been shown to synthesize and provision biotin to supplement the host diet (Gottlieb et al., 2015; Hosokawa et al., 2010b; Pachebat et al., 2013). R. buchneri in I. scapularis possesses 2 copies of the biotin biosynthesis pathway on the pREIS2 plasmid however, its function within the tick is not yet understood (Gillespie et al., 2012). A recently discovered Wolbachia (wCfeT) present in the cat flea Ctenocephalides felis possesses a complete biotin biosynthesis pathway, and it is suspected that it provisions biotin to the host (Driscoll et al., 2020).

\section{Folate (Vitamin B9)}

38 copies of 5 folate genes ( folA, folC, folB, folE, and folP) were found in the D. variabilis metagenome. In the human gut microbiome, nearly all members of Bacteroidetes, Fusobacteria, and Proteobacteria present possessed the complete vitamin B9 biosynthesis pathway accounting for $43 \%$ of the species tested in the human gut (Magnúsdóttir et al., 2015).In arthropods, $R$, rhodnii, Wigglesworthia, Coxiella, and R. buchneri (I. scapularis \& I. pacificus) possess genes necessary for de novo folate biosynthesis (Hunter et al., 2015; Kurtti et al., 2015).

\section{Cobalamin (Vitamin B12)}

42 copies of 13 B12 biosynthesis genes were annotated in the D. variabilis genome composing both the aerobic and anaerobic synthesis pathways. In the human gut microbiome, $42 \%$ of members are capable of synthesizing cobalamin, including all Fusobacteria studied (Magnúsdóttir et al., 2015). Half of Bacteroides are shown to possess the pathway, though it is rarely observed in Actinobacteria or Proteobacteria (Magnúsdóttir et al., 2015).In arthropod microbiomes, only Rhodococcus rhodnii, the endosymbiont of Rhodnius prolixus, has been shown to possess vitamin B12 biosynthesis genes (Pachebat et al., 2013). An analysis of $>11,000$ bacterial species predicted that $37 \%$ were capable of $d e$ novo $\mathrm{B} 12$ biosynthesis; $17 \%$ additional species possessed partial pathways, though they may still be able to synthesize B12 as annotation errors or overlaps in function may have led to the absence of the missing genes (Shelton et al., 2019). 57\% of bacteria in the Actinobacteria phylum $45 \%$ of Proteobacteria, and $30 \%$ of Firmicutes were predicted to produce vitamin B12 (Shelton et al., 2019).

Although metagenomic data for I. scapularis was not obtained here due to low DNA yield from extraction, increasing the total microbial cells recovered from FACS as well as a more efficient DNA concentration method should allow for increased DNA recovery. AxyPrep beads were used for DNA purification; however, a loss in genomic DNA potentially resulted from larger DNA fragments failing to bind to the beads, thus leading to exclusion of this DNA in subsequent bead washes. This did not lead to obvious problems in the $D$. variabilis samples, though, so it is unclear if this is the reason for the issues with I. scapularis. A drastic decrease in DNA was observed in the post-FACS sample compared to the pre-FACS sample; however, this was to be expected as pre-FACS samples contained both eukaryotic and prokaryotic DNA. The appreciable levels of Bradyrhizobium contigs in the D. variabilis metagenome assembly may be due to contamination, as members of this genus have been identified as contaminants in 
DNA extraction kits and can pose challenges for studies involving low microbial biomass (Salter et al., 2014). On the other hand, Bradyrhizobium spp. have been identified in previous 16S studies of tick microbiomes (Thapa et al., 2019) and are also commonly present in soil (VanInsberghe et al., 2015), so it seems reasonable to encounter them in our samples.

With genes from each B-complex vitamin biosynthesis pathway being identified in the $D$. variabilis metagenome, as well as annotated contigs from Francisella spp. we can identify and further study members of the gut microbiome that are potential B-complex producers. This information will allow for more specific targeting of microbiome members for elimination from the host. Clearing these members will uncover their functional role within the host as well as identify potential targets for vector control to mitigate the spread of tick-borne diseases such as Lyme disease and Rocky Mountain spotted fever. 


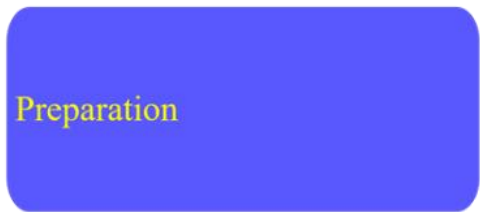

-Surface sterilization ( $5 \%$ bleach, $70 \%$ EtOH, distilled water)

-Dissect tick midgut

- Digest for $60 \mathrm{~min}$ at $37^{\circ} \mathrm{C}$

- Filter $(70 \mu$ pore size $)$

\section{Fluorescence-Activated Cell} Sorting

- Stain with Baclight (Syto9 and Propidium Iodide

- Sort by size $(5 \mu \mathrm{m}) \&$ Syto $9+$

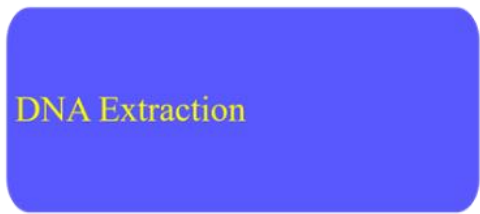

- Arcturus $^{\circledR}$ PicoPure ${ }^{\circledR}$ DNA Extraction Kit

- Axygen AxyPrep purification

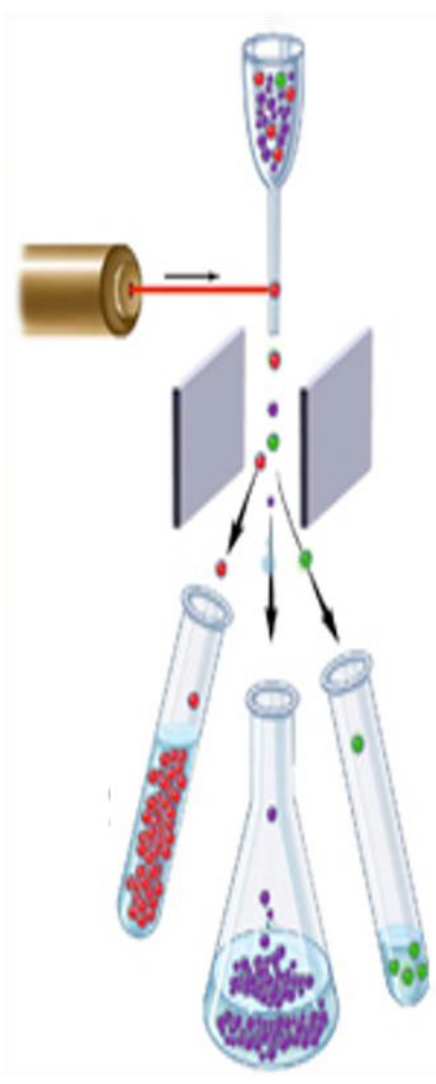

Credit: Institute of Biotechnology, Cornell University
Enrichment Confirmation

- qPCR amplification of beta-actin in pre/post FACS samples

-DNA concentration of pre/post FACS samples with QUBIT 3.0

Metagenome Sequencing \& Assembly

- Illumina MiSeq Paired-End 150

-SPAdes metagenome assembler -Sequence quality check using QUality ASessment Tool for genome assemblies (QUAST)

\section{Analysis}

- Upload to MG-RAST for metagenome assembly annotation.

- B-Complex biosynthesis pathway search

Figure 1: Experimental Design 

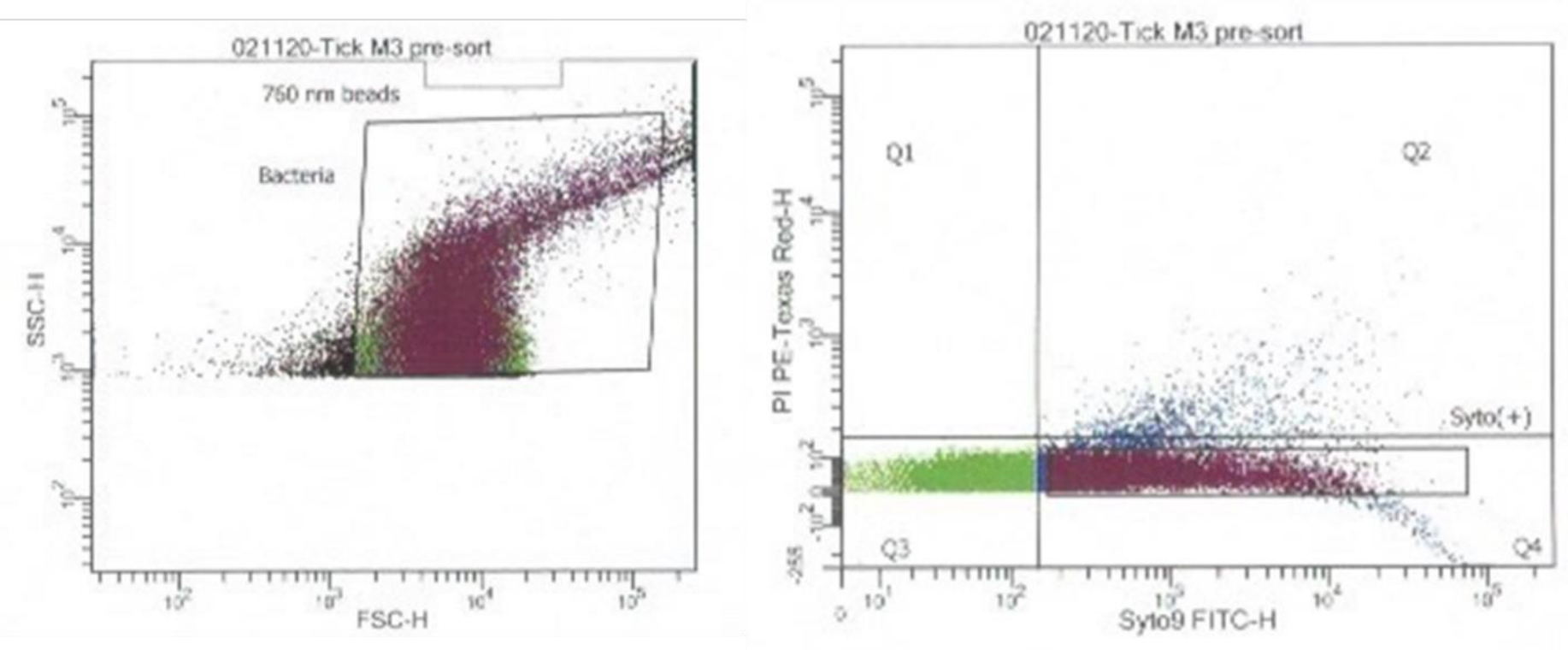

Figure 2: Separation of bacterial cells from eukaryotic cells $(<5 \mu \mathrm{m})($ Left $)$ and separation of live bacterial cells from dead bacterial cells (Syto9+) (Right) 


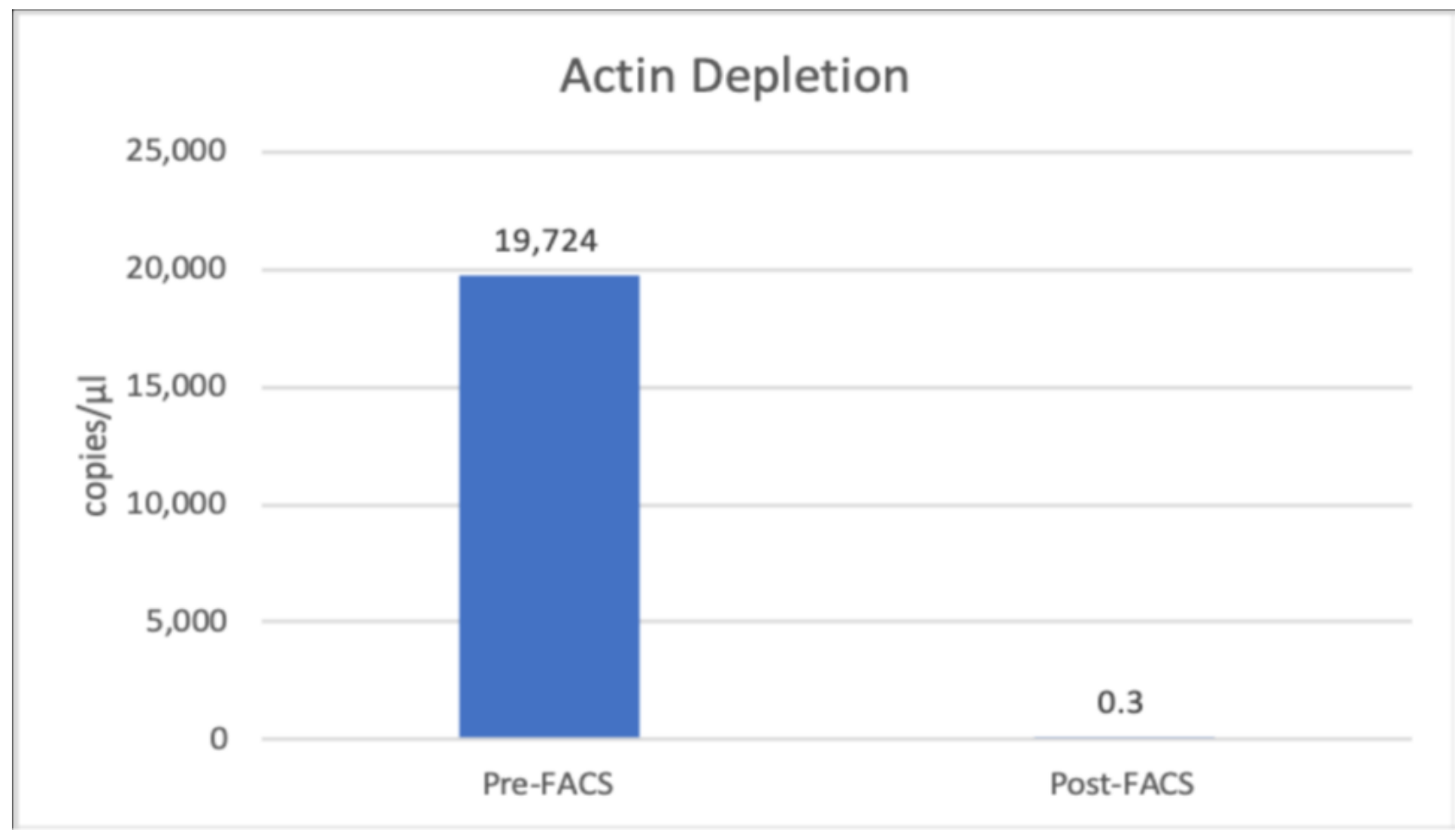

Figure 3: qPCR detection of $D$. variabilis $\beta$-actin in 5-tick pool before and after FACS. 


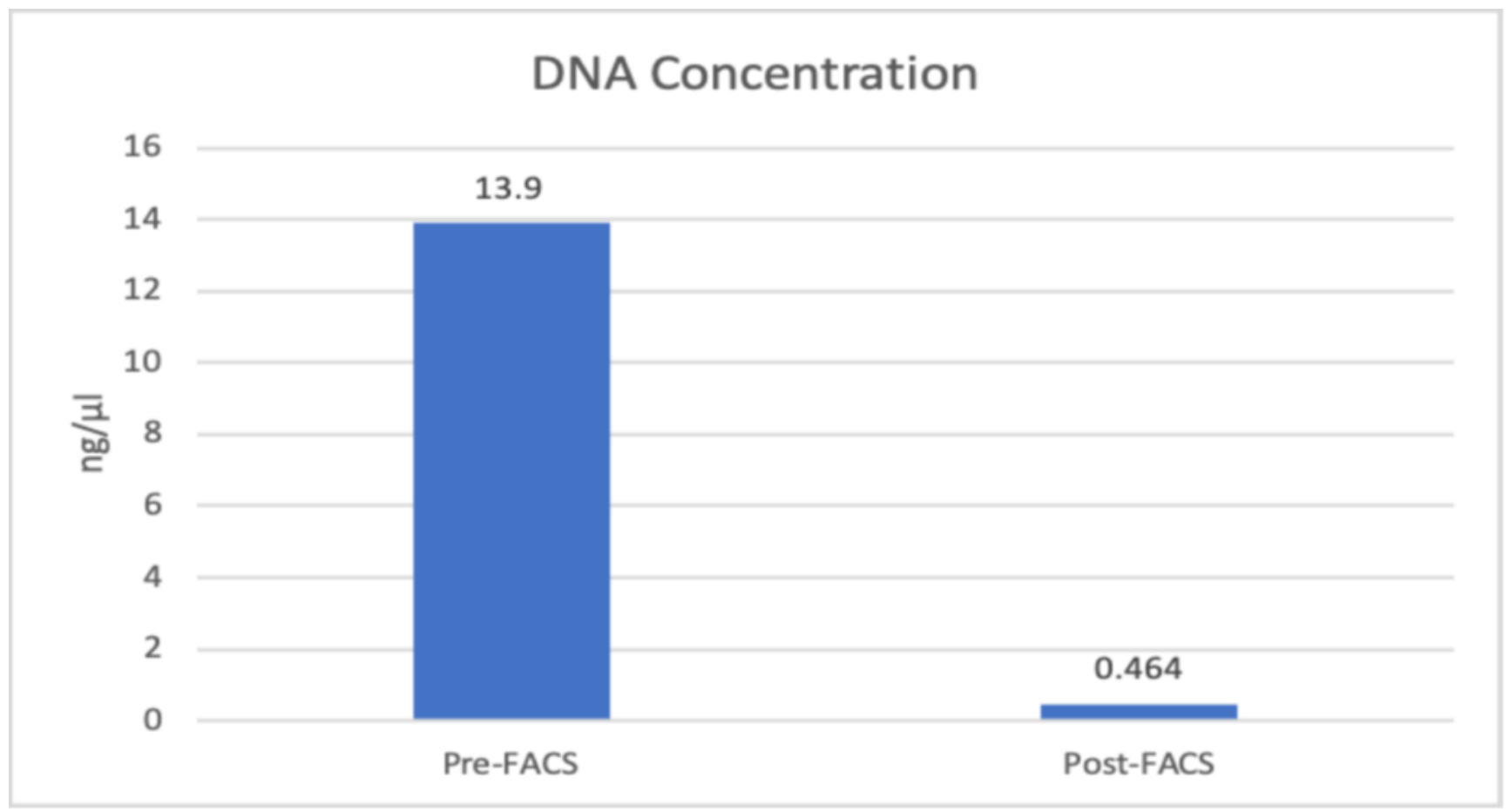

Figure 4: DNA quantification via QUBIT 3.0 of D. variabilis pools before and after FACS. 


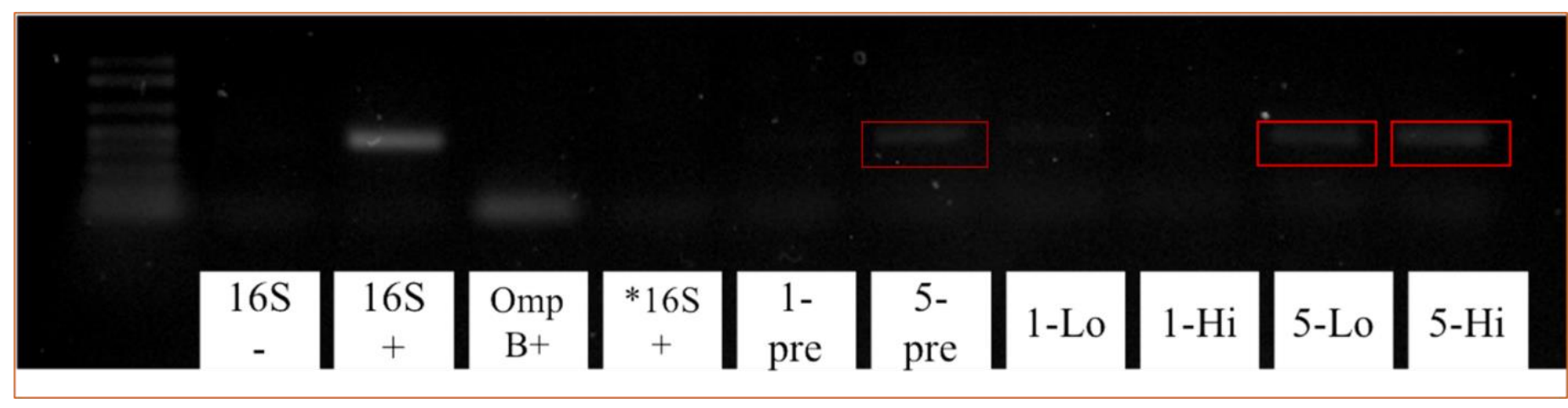

Figure 5: Traditional PCR amplification of bacterial $16 \mathrm{~S}$ present in D. variabilis 5-tick pool before and after FACS 


\begin{tabular}{ll} 
N50 & $8,471 \mathrm{bp}$ \\
\hline L50 & $308 \mathrm{bp}$ \\
\hline \# of Contigs & 164,531 \\
\hline Largest Contig & $300,614 \mathrm{bp}$ \\
\hline Total Length & $68,638,400 \mathrm{bp}$ \\
\hline
\end{tabular}

Table 1: $D$. variabilis metagenome assembly statistics. 


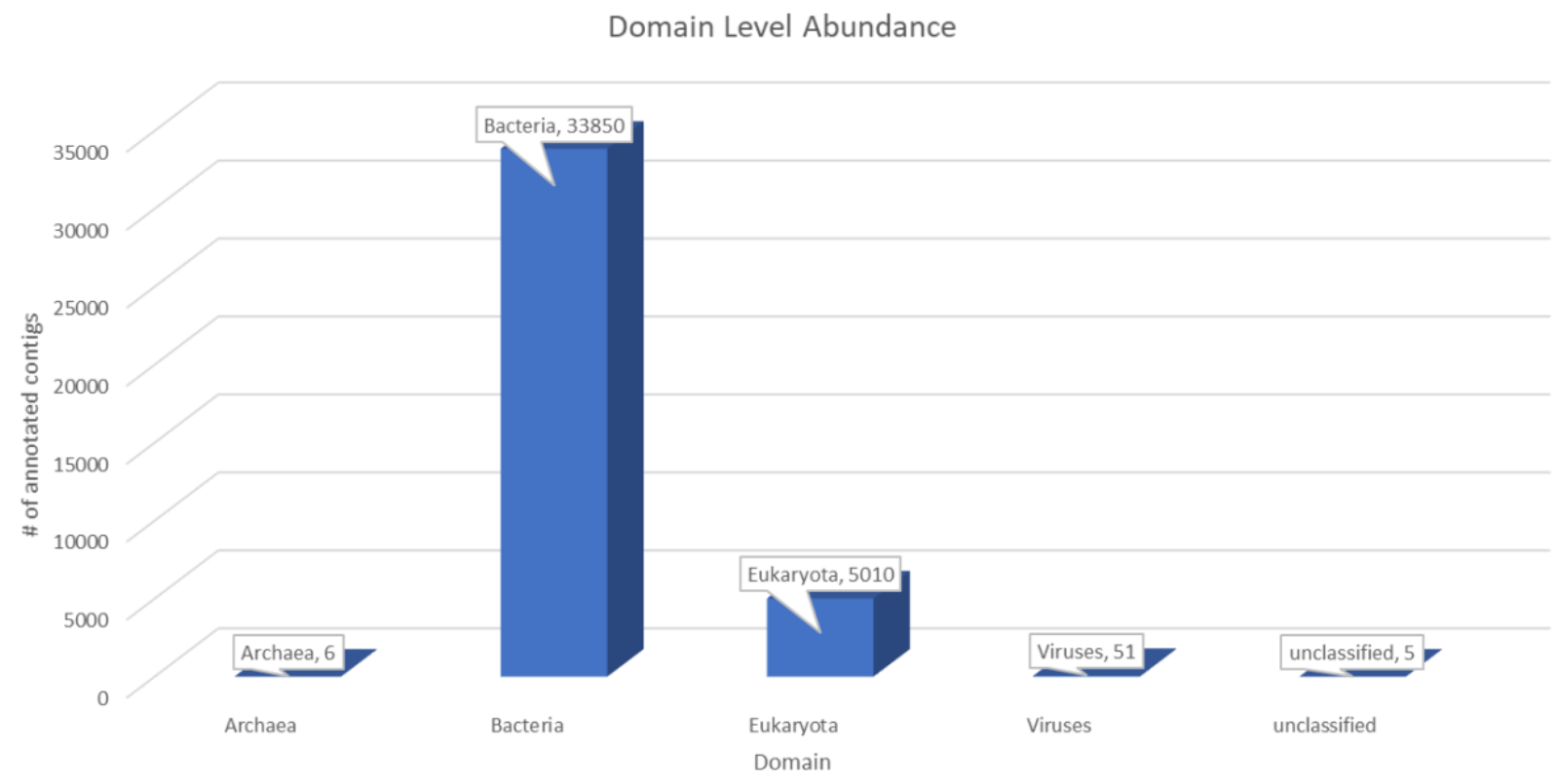

Figure 6: MG-RAST read annotation: domain level abundance. 
Genus Level Abundance

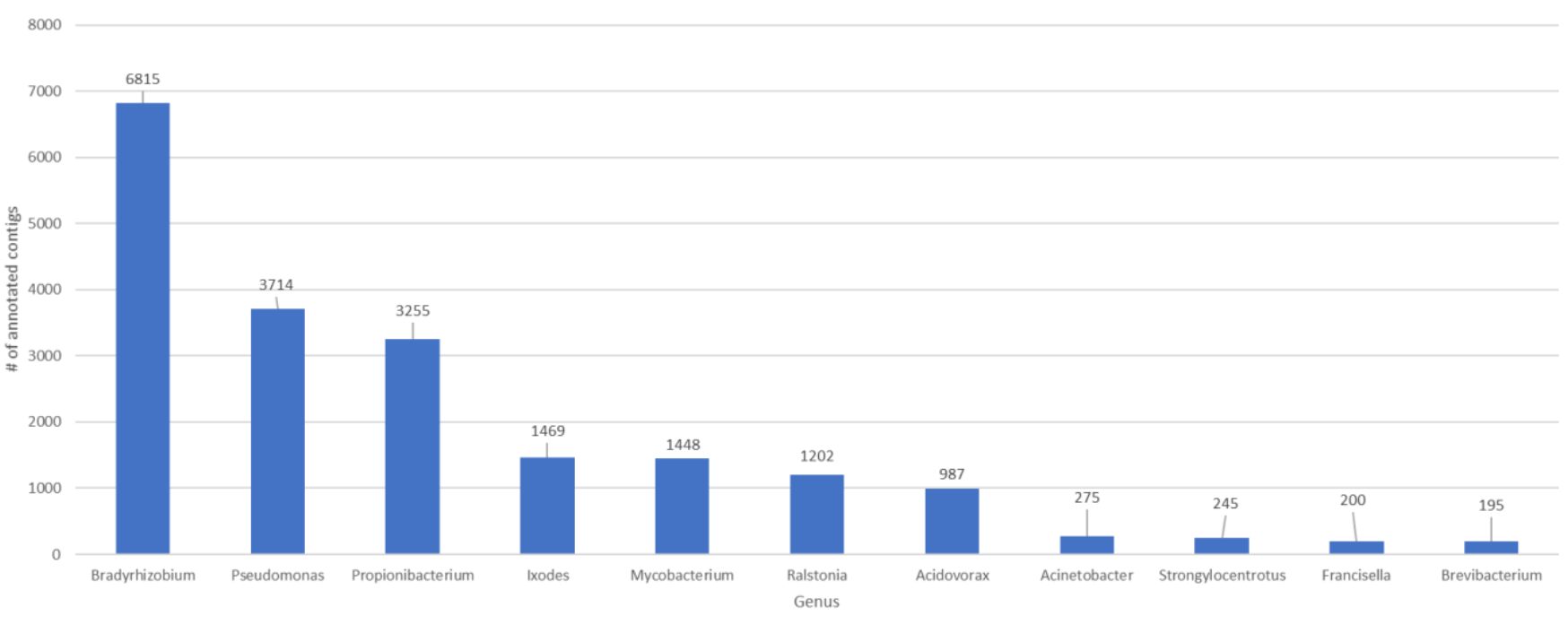

Figure 7: MG-RAST read annotation: genus level abundance. 


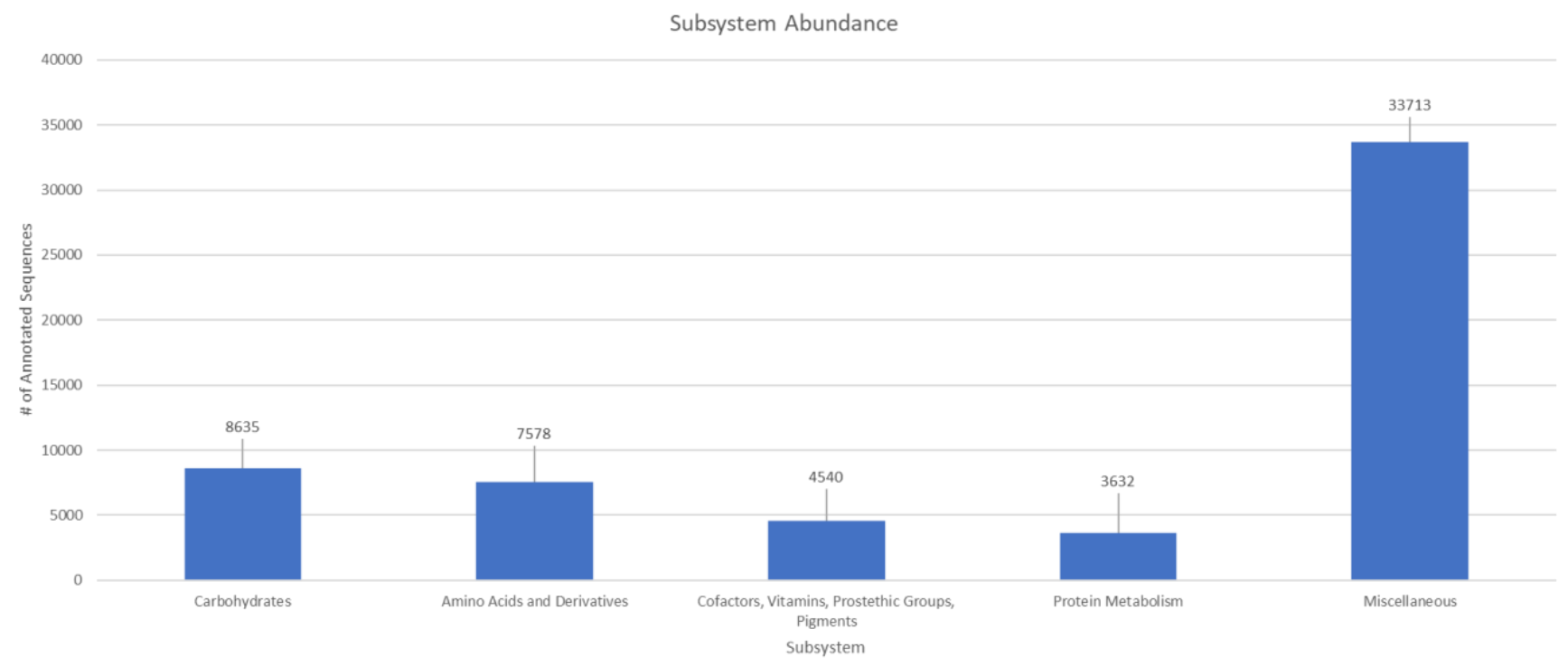

Figure 8: MG-RAST read annotation: subsystem abundance. 
Thiamin Pathway Abundance

60

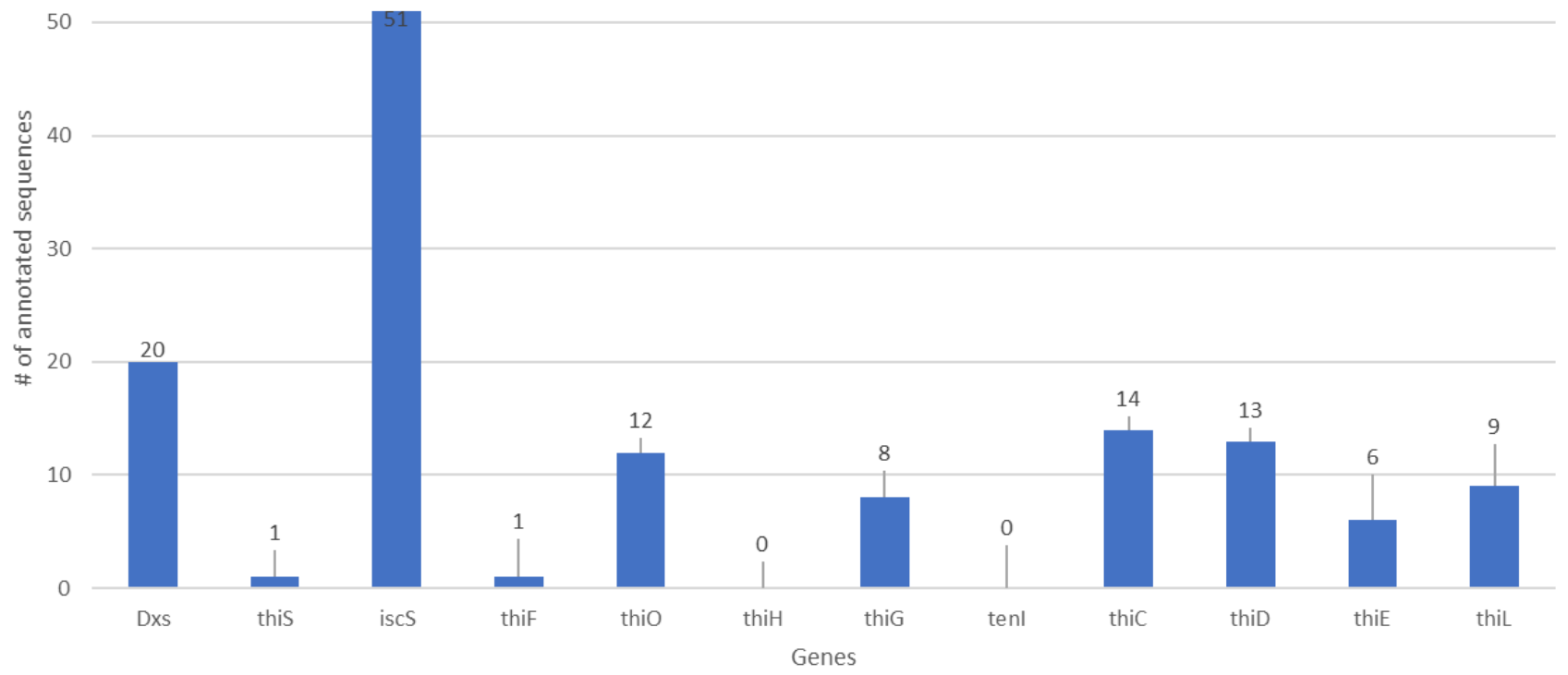

Figure 9: Thiamin biosynthesis pathway abundance in the D. variabilis metagenome. 


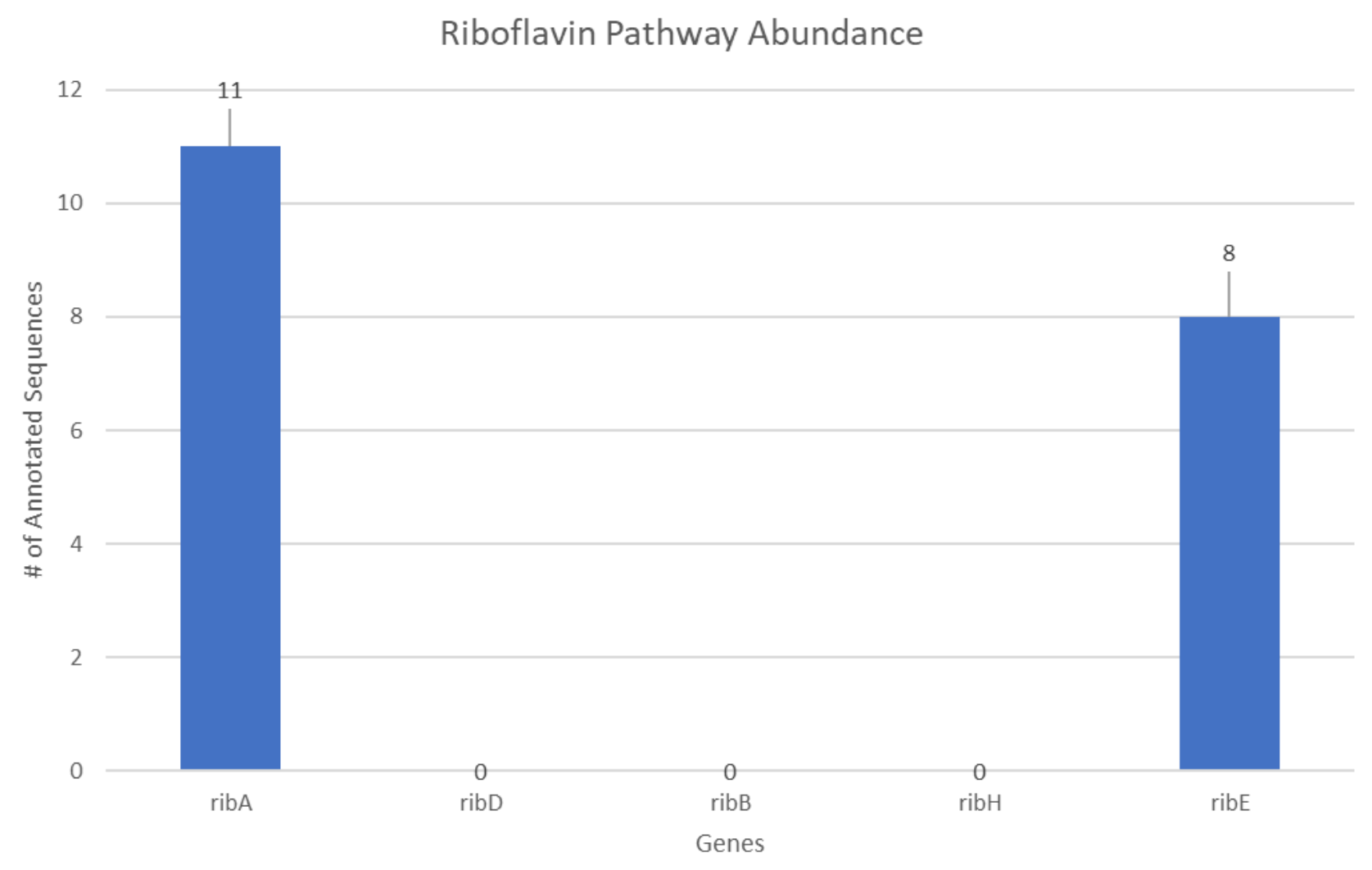

Figure 10: Riboflavin biosynthesis pathway abundance in the $D$. variabilis metagenome. 


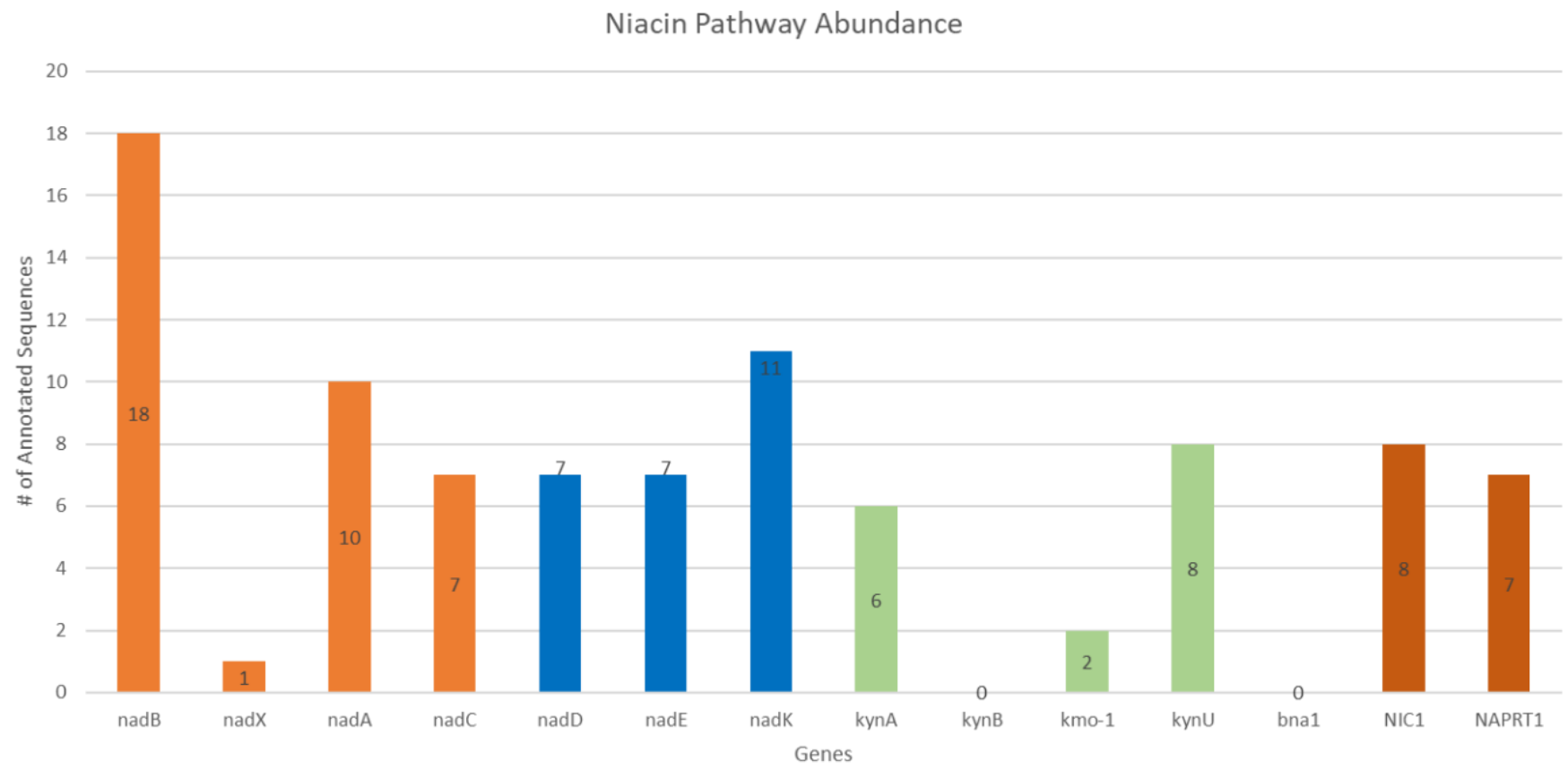

Figure 11: Niacin biosynthesis pathway abundance in the $D$. variabilis metagenome. 


\section{Pantothenic Acid pathway Abundance}

25

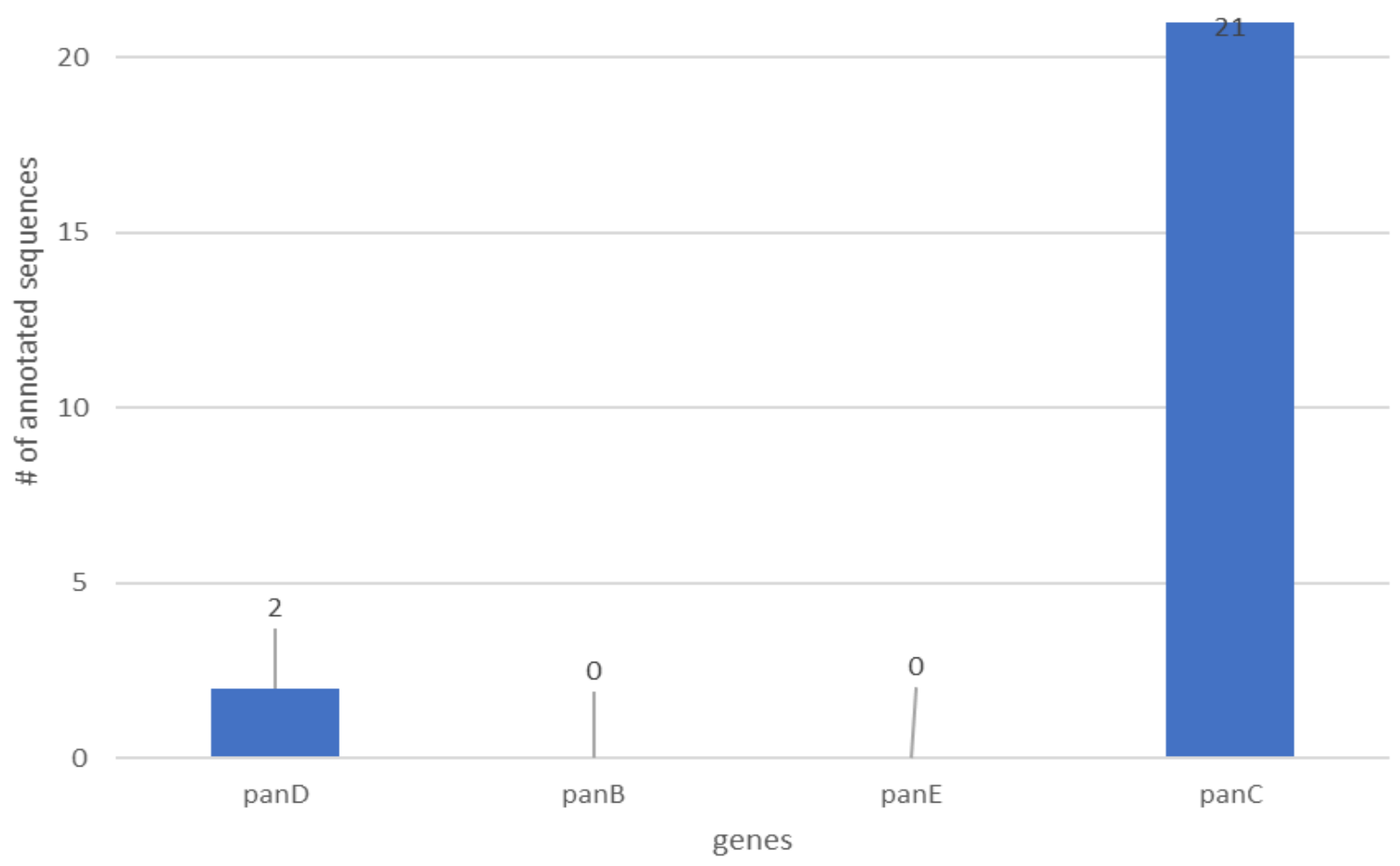

Figure 12: Pantothenic acid biosynthesis pathway abundance in the $D$. variabilis metagenome. 


\section{Pyridoxine Pathway Abundance}

25

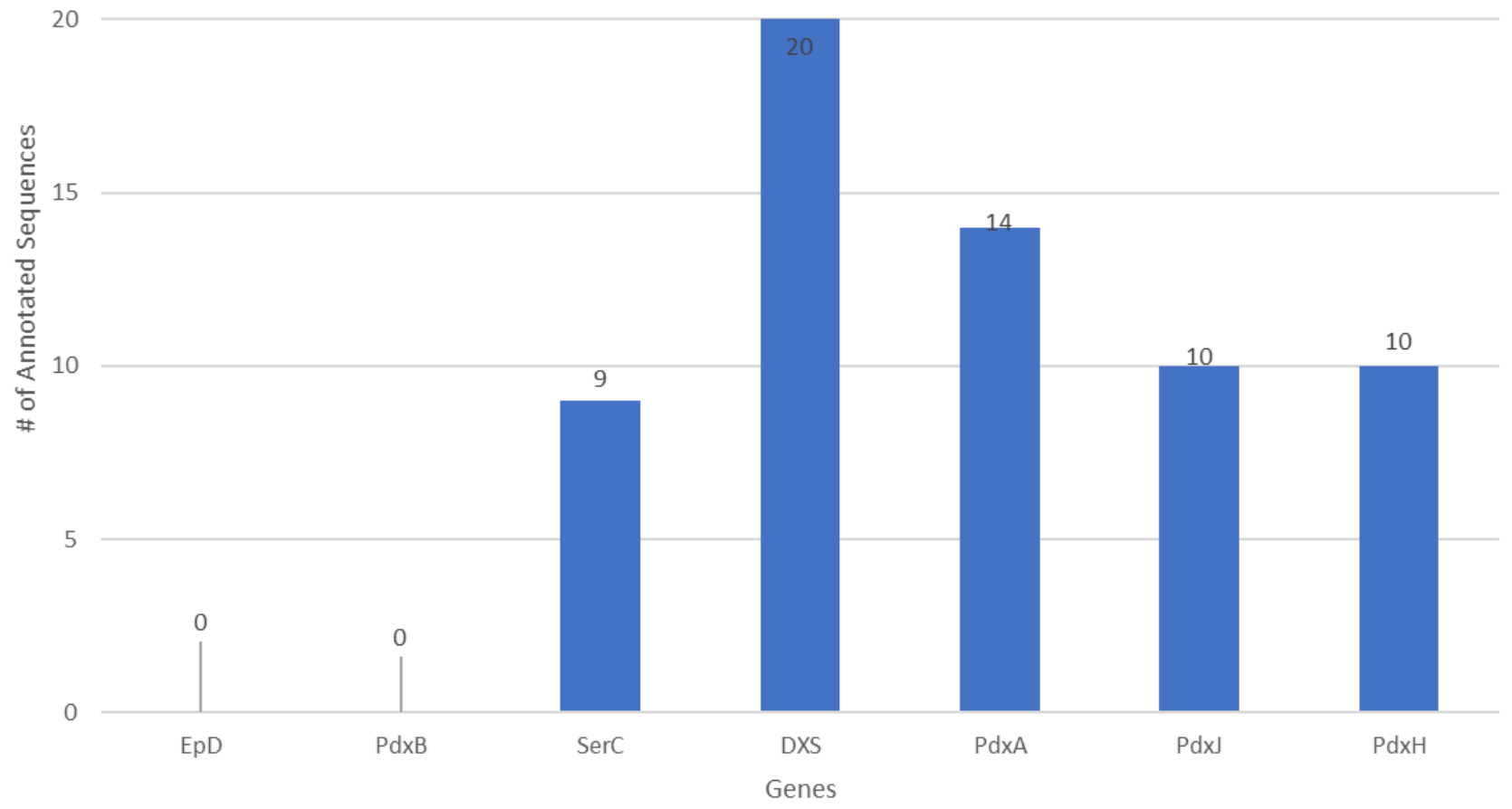

Figure 13: Pyridoxine biosynthesis pathway abundance in $D$. variabilis metagenome. 


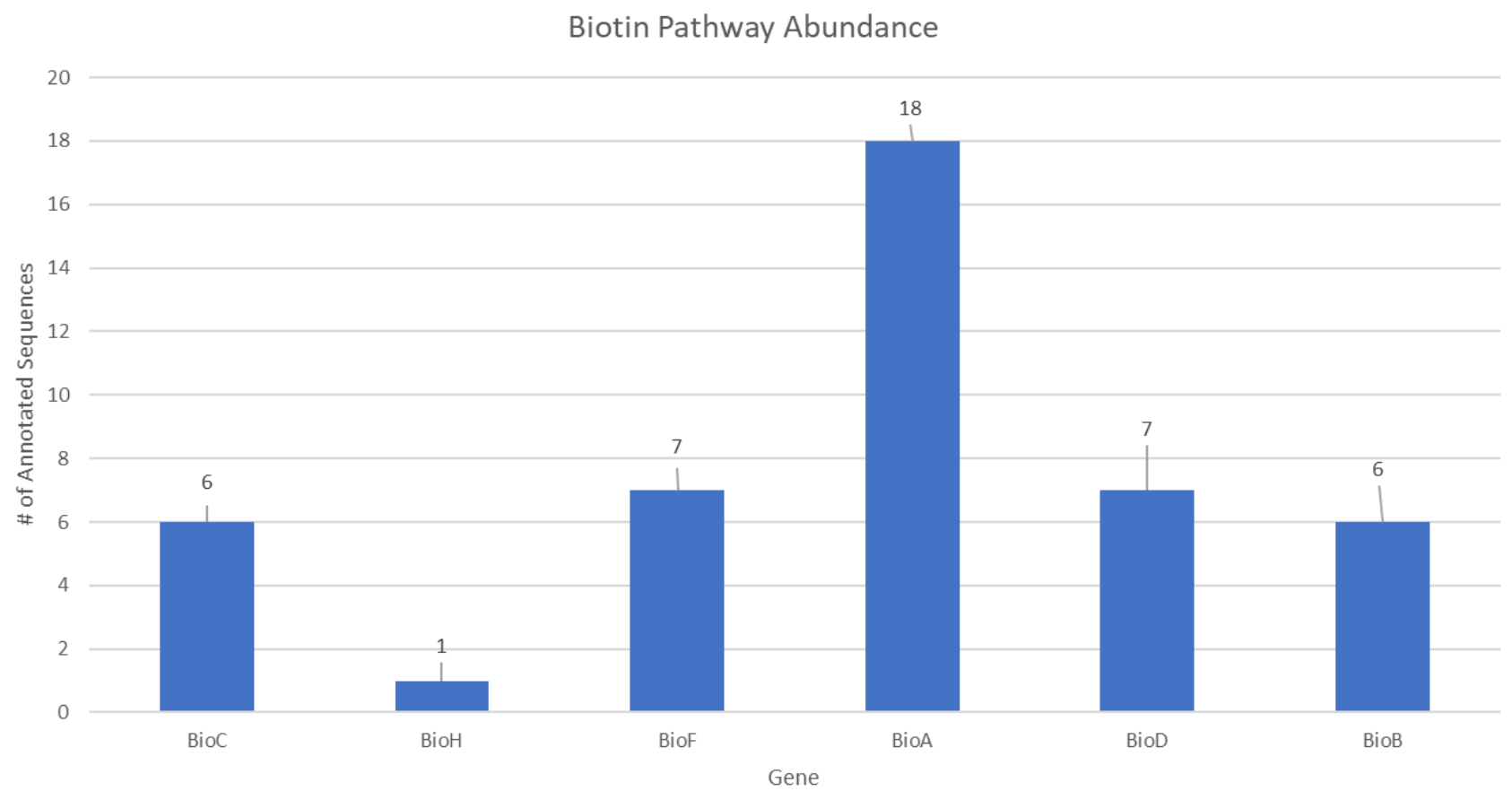

Figure 14: Biotin biosynthesis pathway abundance in the $D$. variabilis metagenome. 
Folate Pathway Abundance

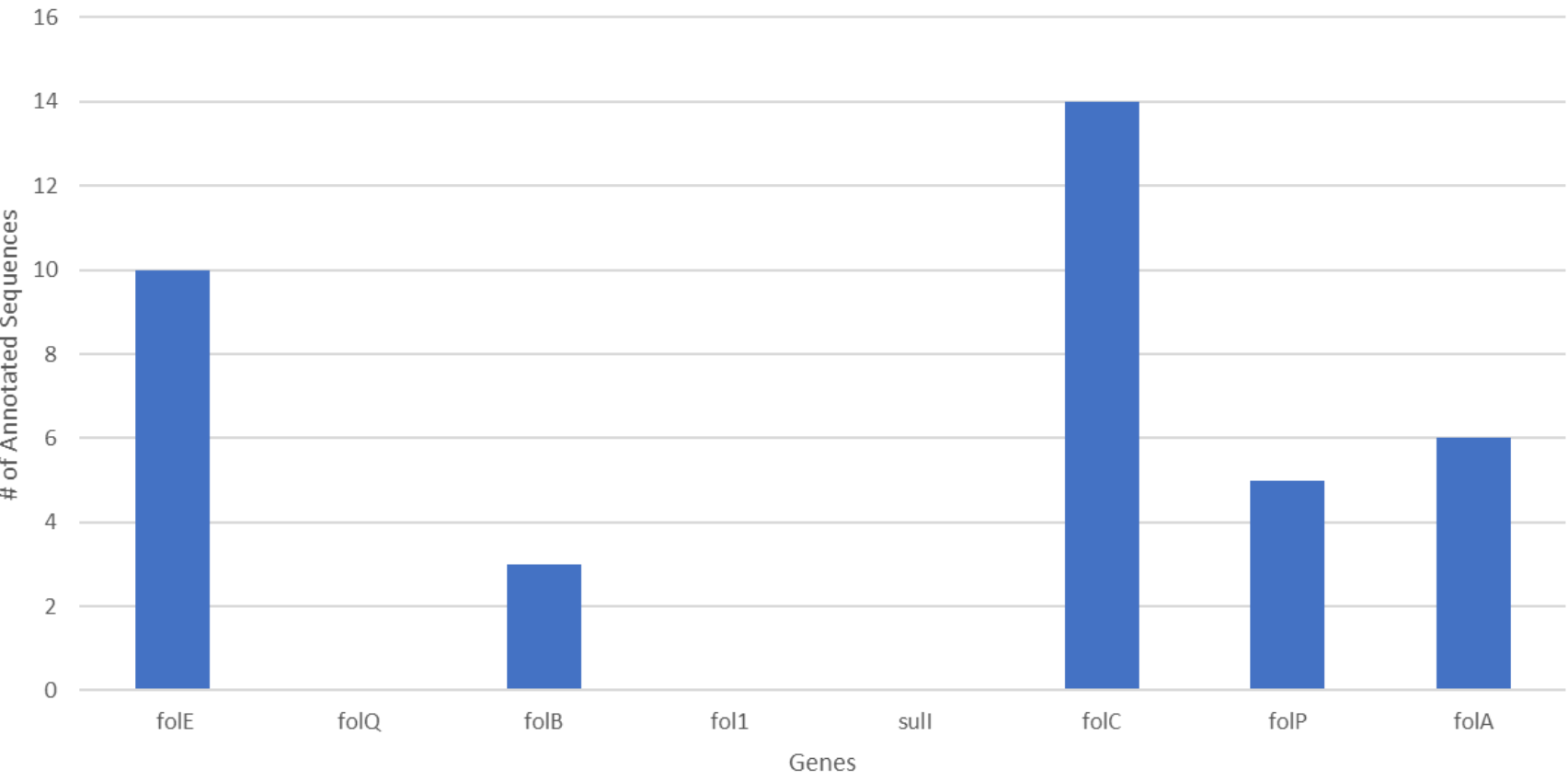

Figure 15: Folate biosynthesis pathway abundance in the $D$. variabilis metagenome. 

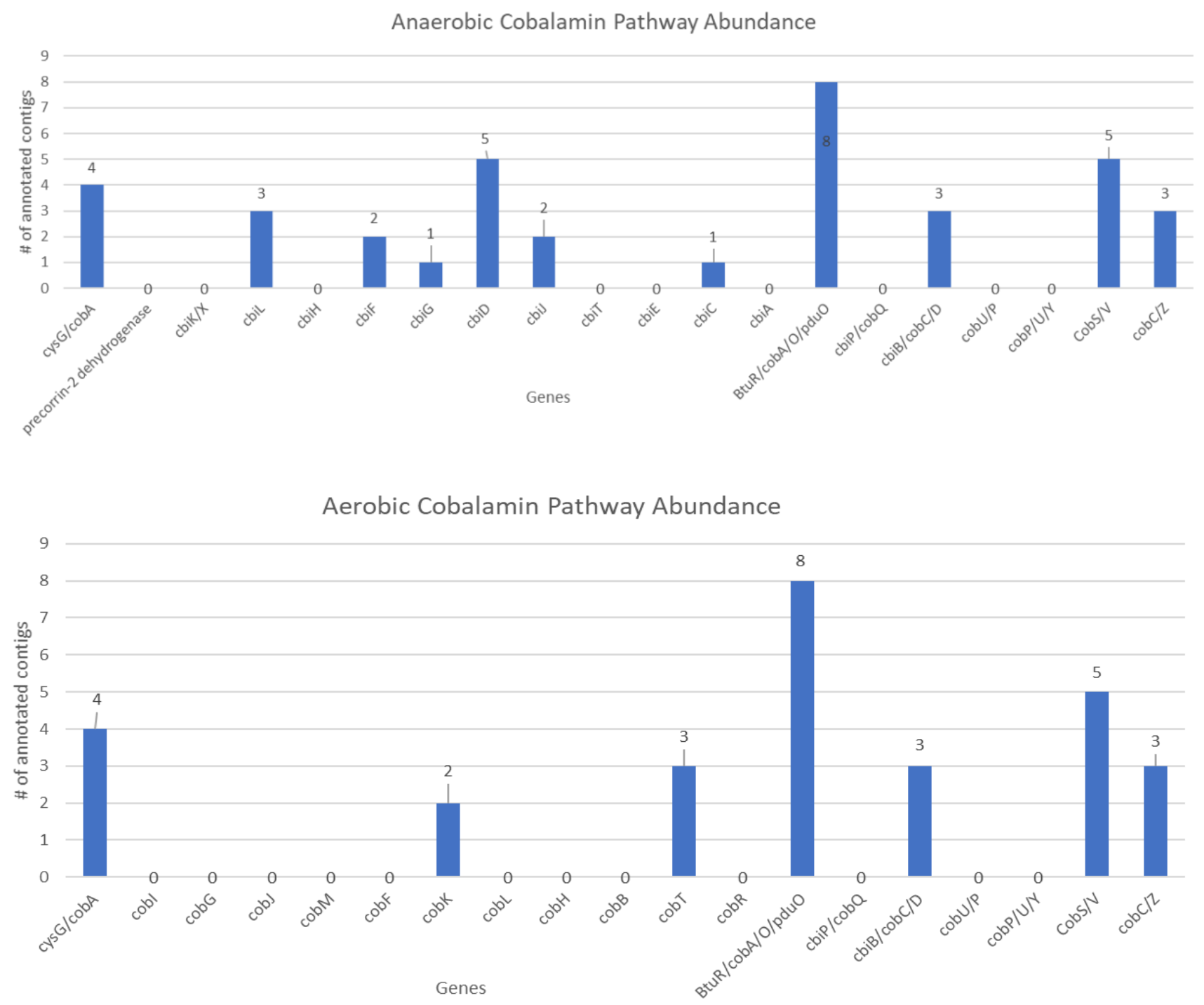

Figure 16: Anaerobic and aerobic cobalamin biosynthesis pathway abundance in the $D$. variabilis metagenome. 


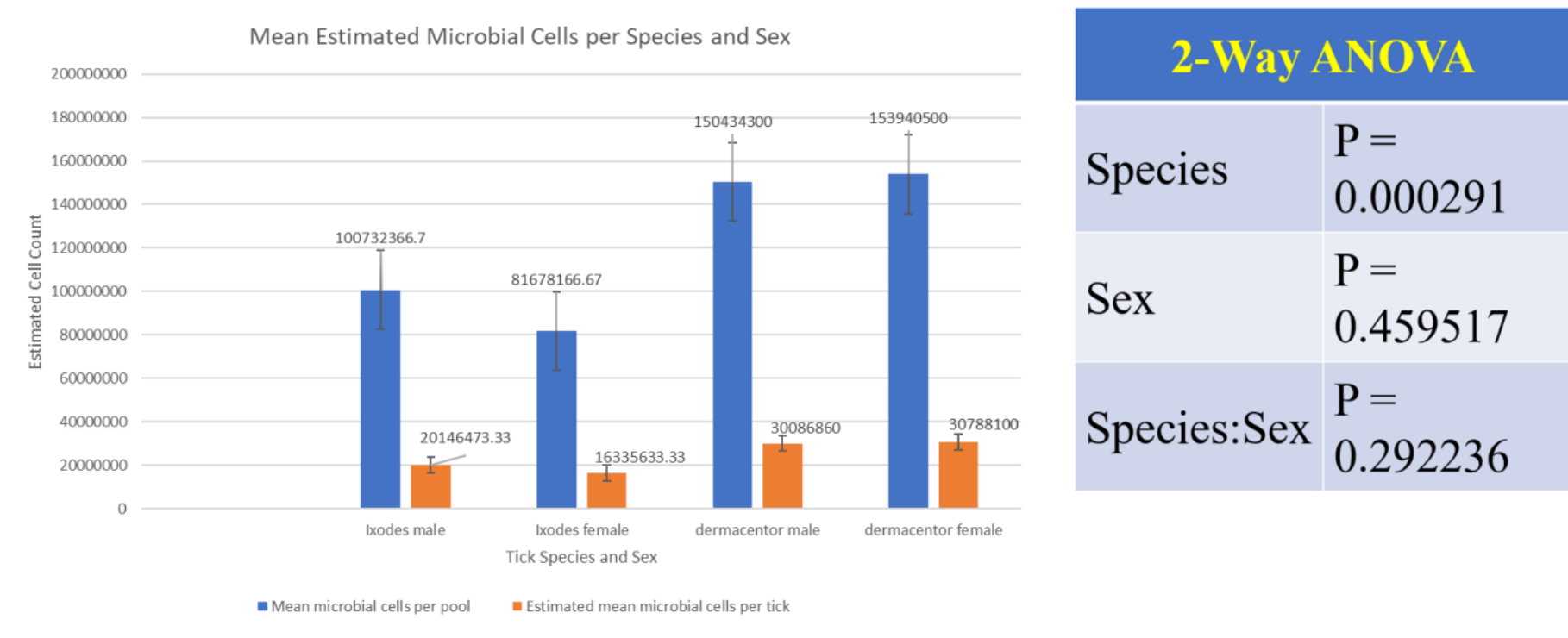

Figure 17: Mean estimation of microbial cell count per pool and per individual tick in each species and sex based on recovered cells from FACS. There was a significant difference between I. scapularis and $D$. variabilis in mean estimated cell count. 


\section{Bibliography}

Abraham, N. M., Liu, L., Jutras, B. L., Yadav, A. K., Narasimhan, S., Gopalakrishnan, V., Ansari, J. M., Jefferson, K. K., Cava, F., Jacobs-Wagner, C., \& Fikrig, E. (2017). Pathogen-mediated manipulation of arthropod microbiota to promote infection. Proceedings of the National Academy of Sciences, 114(5), E781-E790. https://doi.org/10.1073/pnas.1613422114

Adrion, E. R., Aucott, J., Lemke, K. W., \& Weiner, J. P. (2015). Health Care Costs, Utilization and Patterns of Care following Lyme Disease. PLOS ONE, 10(2), e0116767. https://doi.org/10.1371/journal.pone.0116767

Afzelius, B. A., Alberti, G., Dallai, R., Godula, J., \& Witalinski, W. (1989). Virus- and rickettsia-infected sperm cells in arthropods. Journal of Invertebrate Pathology, 53(3), 365-377. https://doi.org/10.1016/0022-2011(89)90102-X

Ahantarig, A., Trinachartvanit, W., Baimai, V., \& Grubhoffer, L. (2013). Hard ticks and their bacterial endosymbionts (or would be pathogens). Folia Microbiologica, 58(5), 419-428. https://doi.org/10.1007/s12223-013-0222-1

Akman, L., Yamashita, A., Watanabe, H., Oshima, K., Shiba, T., Hattori, M., \& Aksoy, S. (2002). Genome sequence of the endocellular obligate symbiont of tsetse flies, Wigglesworthia glossinidia. Nature Genetics, 32(3), 402-407. https://doi.org/10.1038/ng986

Al-Khafaji, A. M., Armstrong, S. D., Varotto Boccazzi, I., Gaiarsa, S., Sinha, A., Li, Z., Sassera, D., Carlow, C. K. S., Epis, S., \& Makepeace, B. L. (2020). Rickettsia buchneri, symbiont of the deer tick Ixodes scapularis, can colonise the salivary glands of its host. Ticks and Tick-Borne Diseases, 11(1), 101299. https://doi.org/10.1016/j.ttbdis.2019.101299 
Almeida, A. P., Marcili, A., Leite, R. C., Nieri-Bastos, F. A., Domingues, L. N., Martins, J. R., \& Labruna, M. B. (2012). Coxiella symbiont in the tick Ornithodoros rostratus (Acari: Argasidae). Ticks and Tick-Borne Diseases, 3(4), 203-206. https://doi.org/10.1016/j.ttbdis.2012.02.003

Anderson, J. F., \& Magnarelli, L. A. (2008). Biology of Ticks. Infectious Disease Clinics of North America, 22(2), 195-215. https://doi.org/10.1016/j.idc.2007.12.006

Andreotti, R., Pérez de León, A. A., Dowd, S. E., Guerrero, F. D., Bendele, K. G., \& Scoles, G. A. (2011). Assessment of bacterial diversity in the cattle tick Rhipicephalus (Boophilus) microplus through tag-encoded pyrosequencing. BMC Microbiology, 11(1), 6. https://doi.org/10.1186/1471-2180-11-6

Aubry, P., \& Geale, D. W. (2011). A Review of Bovine Anaplasmosis: Review of Bovine Anaplasmosis. Transboundary and Emerging Diseases, 58(1), 1-30. https://doi.org/10.1111/j.1865-1682.2010.01173.x

Balasubramanian, S. (2011). Sequencing nucleic acids: From chemistry to medicine. Chemical Communications, 47(26), 7281-7286. https://doi.org/10.1039/c1cc11078k

Beard, C. B., Cordon-Rosales, C., \& Durvasula, R. V. (2002). Bacterial Symbionts of the Triatominae and Their Potential Use in Control of Chagas Disease Transmission. Annual Review of Entomology, 47(1), 123-141. https://doi.org/10.1146/annurev.ento.47.091201.145144

Beninati, T., Lo, N., Sacchi, L., Genchi, C., Noda, H., \& Bandi, C. (2004). A Novel AlphaProteobacterium Resides in the Mitochondria of Ovarian Cells of the Tick Ixodes ricinus. Applied and Environmental Microbiology, 70(5), 2596-2602. https://doi.org/10.1128/AEM.70.5.2596-2602.2004 
Bennett, G. M., \& Moran, N. A. (2013). Small, Smaller, Smallest: The Origins and Evolution of Ancient Dual Symbioses in a Phloem-Feeding Insect. Genome Biology and Evolution, 5(9), 1675-1688. https://doi.org/10.1093/gbe/evt118

Benson, M. J., Gawronski, J. D., Eveleigh, D. E., \& Benson, D. R. (2004). Intracellular Symbionts and Other Bacteria Associated with Deer Ticks (Ixodes scapularis) from Nantucket and Wellfleet, Cape Cod, Massachusetts. Applied and Environmental Microbiology, 70(1), 616-620. https://doi.org/10.1128/AEM.70.1.616-620.2004

Boyd, B. M., Allen, J. M., Koga, R., Fukatsu, T., Sweet, A. D., Johnson, K. P., \& Reed, David. L. (2016). Two Bacterial Genera, Sodalis and Rickettsia, Associated with the Seal Louse Proechinophthirus fluctus (Phthiraptera: Anoplura). Applied and Environmental Microbiology, 82(11), 3185-3197.

Broderick, N. A., \& Lemaitre, B. (2012). Gut-associated microbes of Drosophila melanogaster. Gut Microbes, 3(4), 307-321. https://doi.org/10.4161/gmic.19896

Budachetri, K., Browning, R. E., Adamson, S. W., Dowd, S. E., Chao, C.-C., Ching, W.-M., \& Karim, S. (2014). An Insight Into the Microbiome of the Amblyomma maculatum (Acari: Ixodidae). Journal of Medical Entomology, 51(1), 119-129. https://doi.org/10.1603/ME12223

Burgdorfer, W., \& Owen, R. C. (1956). Experimental Studies on Argasid Ticks as Possible Vectors of Tularemia. Journal of Infectious Diseases, 98(1), 67-74. https://doi.org/10.1093/infdis/98.1.67

Carmody, R. N., Gerber, G. K., Luevano, J. M., Gatti, D. M., Somes, L., Svenson, K. L., \& Turnbaugh, P. J. (2015). Diet Dominates Host Genotype in Shaping the Murine Gut 
Microbiota. Cell Host \& Microbe, 17(1), 72-84.

https://doi.org/10.1016/j.chom.2014.11.010

Carpi, G., Cagnacci, F., Wittekindt, N. E., Zhao, F., Qi, J., Tomsho, L. P., Drautz, D. I., Rizzoli, A., \& Schuster, S. C. (2011). Metagenomic Profile of the Bacterial Communities Associated with Ixodes ricinus Ticks. PLoS ONE, 6(10), e25604. https://doi.org/10.1371/journal.pone.0025604

Chicana, B., Couper, L. I., Kwan, J. Y., Tahiraj, E., \& Swei, A. (2019). Comparative Microbiome Profiles of Sympatric Tick Species From the Far-Western United States. Insects, 10(10), 353. https://doi.org/10.3390/insects10100353

Childs, J. E., \& Paddock, C. D. (2002). Passive surveillance as an instrument to identify risk factors for fatal Rocky Mountain spotted fever: Is there more to learn? The American Journal of Tropical Medicine and Hygiene, 66(5), 450-457. https://doi.org/10.4269/ajtmh.2002.66.450

Chmelar, J., Calvo, E., Pedra, J. H. F., Francischetti, I. M. B., \& Kotsyfakis, M. (2012). Tick salivary secretion as a source of antihemostatics. Journal of Proteomics, 75(13), 38423854. https://doi.org/10.1016/j.jprot.2012.04.026

Clayton, K. A., Gall, C. A., Mason, K. L., Scoles, G. A., \& Brayton, K. A. (2015). The characterization and manipulation of the bacterial microbiome of the Rocky Mountain wood tick, Dermacentor andersoni. Parasites \& Vectors, 8(1), 632. https://doi.org/10.1186/s13071-015-1245-z

Darby, A. C., Choi, J. H., Wilkes, T., \& Hughes, M. A. (2010). Characteristics of the genome of Arsenophonus nasoniae, son-killer bacterium of the wasp Nasonia vitripennis. Insect Molecular Biology, 19, 75-89. 
de la Fuente, José, \& Contreras, M. (2015). Tick vaccines: Current status and future directions. Expert Review of Vaccines, 14(10), 1367-1376. https://doi.org/10.1586/14760584.2015.1076339

de la Fuente, Jose, Estrada-Pena, A., Venzal, J. M., Kocan, K. M., \& Soneshine, D. E. (2008). Overview: Ticks as vectors of pathogens that cause disease in humans and animals. Frontiers in Bioscience, Volume(13), 6938. https://doi.org/10.2741/3200

Deguchi, Y., Morishita, T., \& Mutai, M. (1985). Comparative Studies on Synthesis of Watersoluble Vitamins among HumanSpecies of Bifidobacteria.

Dennison, N. J., Jupatanakul, N., \& Dimopoulos, G. (2014). The mosquito microbiota influences vector competence for human pathogens. Current Opinion in Insect Science, 3, 6-13. https://doi.org/10.1016/j.cois.2014.07.004

Dergousoff, S. J., \& Chilton, N. B. (2010). Detection of a new Arsenophonus-type bacterium in Canadian populations of the Rocky Mountain wood tick, Dermacentor andersoni. Experimental and Applied Acarology, 52(1), 85-91. https://doi.org/10.1007/s10493-0109340-5

diCenzo, G. C., \& Finan, T. M. (2017). The Divided Bacterial Genome: Structure, Function, and Evolution. Microbiology and Molecular Biology Reviews, 81(3), e00019-17, e00019-17. https://doi.org/10.1128/MMBR.00019-17

Drexler, N. A., Traeger, M. S., McQuiston, J. H., Williams, V., Hamilton, C., \& Regan, J. J. (2015). Medical and Indirect Costs Associated with a Rocky Mountain Spotted Fever Epidemic in Arizona, 2002-2011. The American Journal of Tropical Medicine and Hygiene, 93(3), 549-551. https://doi.org/10.4269/ajtmh.15-0104 
Driscoll, T. P., Verhoeve, V. I., Brockway, C., Shrewsberry, D. L., Plumer, M. L., Sevdalis, S. E., Beckmann, J. F., Krueger Prelesnik, L. M., Macaluso, K. R., Azad, A. F., \& Gillespie, J. J. (2020). Evolution of Wolbachia Mutualism and Reproductive Parasitism: Insight from Two Novel Strains that Co-infect Cat Fleas [Preprint]. Genomics. https://doi.org/10.1101/2020.06.01.128066

Driscoll, T. P., Verhoeve, V. I., Guillotte, M. L., Lehman, S. S., Rennoll, S. A., Beier-Sexton, M., Rahman, M. S., Azad, A. F., \& Gillespie, J. J. (2017). Wholly Rickettsia! Reconstructed Metabolic Profile of the Quintessential Bacterial Parasite of Eukaryotic Cells. MBio, 8(5), mBio.00859-17, e00859-17. https://doi.org/10.1128/mBio.00859-17

Eisen, R. J., \& Eisen, L. (2018). The Blacklegged Tick, Ixodes scapularis: An Increasing Public Health Concern. Trends in Parasitology, 34(4), 295-309. https://doi.org/10.1016/j.pt.2017.12.006

Epis, S., Sassera, D., Beninati, T., Lo, N., Beati, L., Piesman, J., Rinaldi, L., McCOY, K. D., Torina, A., Sacchi, L., Clementi, E., Genchi, M., Magnino, S., \& Bandi, C. (2008). Midichloria mitochondrii is widespread in hard ticks (Ixodidae) and resides in the mitochondria of phylogenetically diverse species. Parasitology, 135(4), 485-494. https://doi.org/10.1017/S0031182007004052

Ewing, S. A., Dawson, J. E., Kocan, A. A., Barker, R. W., Warner, C. K., \& Panciera, R. J. (1995). Experimental Transmission of Ehrlichia Chaffeensis (Rickettsiales: Ehrlichieae) Among White-Tailed Deer by Amblyomma Americanum (Acari: Ixodidae). Journal of Medical Entomology, 32(3), 368-374. https://doi.org/10.1093/jmedent/32.3.368

Gall, C. A., Reif, K. E., Scoles, G. A., Mason, K. L., Mousel, M., Noh, S. M., \& Brayton, K. A. (2016). The bacterial microbiome of Dermacentor andersoni ticks influences pathogen 
susceptibility. The ISME Journal, 10(8), 1846-1855.

https://doi.org/10.1038/ismej.2015.266

Gerth, M., Gansauge, M.-T., Weigert, A., \& Bleidorn, C. (2014). Phylogenomic analyses uncover origin and spread of the Wolbachia pandemic. Nature Communications, 5(1), 5117. https://doi.org/10.1038/ncomms6117

Gillespie, J. J., Joardar, V., Williams, K. P., Driscoll, T., Hostetler, J. B., Nordberg, E., Shukla, M., Walenz, B., Hill, C. A., Nene, V. M., Azad, A. F., Sobral, B. W., \& Caler, E. (2012). A Rickettsia Genome Overrun by Mobile Genetic Elements Provides Insight into the Acquisition of Genes Characteristic of an Obligate Intracellular Lifestyle. Journal of Bacteriology, 194(2), 376-394. https://doi.org/10.1128/JB.06244-11

Gofton, A. W., Oskam, C. L., Lo, N., Beninati, T., Wei, H., McCarl, V., Murray, D. C., Paparini, A., Greay, T. L., Holmes, A. J., Bunce, M., Ryan, U., \& Irwin, P. (2015). Inhibition of the endosymbiont "Candidatus Midichloria mitochondrii”" during 16S rRNA gene profiling reveals potential pathogens in Ixodes ticks from Australia. Parasites \& Vectors, 8(1), 345. https://doi.org/10.1186/s13071-015-0958-3

Gottlieb, Y., Lalzar, I., \& Klasson, L. (2015). Distinctive Genome Reduction Rates Revealed by Genomic Analyses of Two Coxiella- Like Endosymbionts in Ticks. Genome Biology and Evolution, 7(6), 1779-1796. https://doi.org/10.1093/gbe/evv108

Gray, J. S., Dautel, H., Estrada-Peña, A., Kahl, O., \& Lindgren, E. (2009). Effects of Climate Change on Ticks and Tick-Borne Diseases in Europe. Interdisciplinary Perspectives on Infectious Diseases, 2009, 1-12. https://doi.org/10.1155/2009/593232 
Greay, T. L., Gofton, A. W., Paparini, A., Ryan, U. M., Oskam, C. L., \& Irwin, P. J. (2018). Recent insights into the tick microbiome gained through next-generation sequencing. Parasites \& Vectors, 11(1), 12. https://doi.org/10.1186/s13071-017-2550-5

Gurevich, A., Saveliev, V., Vyahhi, N., \& Tesler, G. (2013). QUAST: Quality assessment tool for genome assemblies. Bioinformatics, 29(8), 1072-1075. https://doi.org/10.1093/bioinformatics/btt086

Gurfield, N., Grewal, S., Cua, L. S., Torres, P. J., \& Kelley, S. T. (2017). Endosymbiont interference and microbial diversity of the Pacific coast tick, Dermacentor occidentalis, in San Diego County, California. PeerJ, 5, e3202. https://doi.org/10.7717/peerj.3202

Hagen, R., Verhoeve, V. I., Gillespie, J. J., \& Driscoll, T. P. (2018). Conjugative Transposons and Their Cargo Genes Vary across Natural Populations of Rickettsia buchneri Infecting the Tick Ixodes scapularis. Genome Biology and Evolution, 10(12), 3218-3229. https://doi.org/10.1093/gbe/evy247

Han, K., Li, Z., Peng, R., Zhu, L., Zhou, T., Wang, L., Li, S., Zhang, X., Hu, W., Wu, Z., Qin, N., \& Li, Y. (2013). Extraordinary expansion of a Sorangium cellulosum genome from an alkaline milieu. Scientific Reports, 3(1), 2101. https://doi.org/10.1038/srep02101

Hang, X., Zeng, Q., Zeng, L., Jia, J., \& Bi, H. (2019). Functional Replacement of the BioC and BioH Proteins of Escherichia Coli Biotin Precursor Biosynthesis by Ehrlichia Chaffeensis Novel Proteins. Current Microbiology, 76, 626-636.

Hartelt, K., Oehme, R., Frank, H., Brockmann, S. O., Hassler, D., \& Kimmig, P. (2004). Pathogens and symbionts in ticks: Prevalence of Anaplasma phagocytophilum (Ehrlichia sp.), Wolbachia sp., Rickettsia sp., and Babesia sp. in Southern Germany. International 
Journal of Medical Microbiology Supplements, 293, 86-92.

https://doi.org/10.1016/S1433-1128(04)80013-5

Hawlena, H., Rynkiewicz, E., Toh, E., Alfred, A., Durden, L. A., Hastriter, M. W., Nelson, D. E., Rong, R., Munro, D., Dong, Q., Fuqua, C., \& Clay, K. (2013). The arthropod, but not the vertebrate host or its environment, dictates bacterial community composition of fleas and ticks. The ISME Journal, 7(1), 221-223. https://doi.org/10.1038/ismej.2012.71

Heather, J. M., \& Chain, B. (2016). The sequence of sequencers: The history of sequencing DNA. Genomics, 107(1), 1-8. https://doi.org/10.1016/j.ygeno.2015.11.003

Heisig, M., Abraham, N. M., Liu, L., Neelakanta, G., Mattessich, S., Sultana, H., Shang, Z., Ansari, J. M., Killiam, C., Walker, W., Cooley, L., Flavell, R. A., Agaisse, H., \& Fikrig, E. (2014). Antivirulence Properties of an Antifreeze Protein. Cell Reports, 9(2), 417-424. https://doi.org/10.1016/j.celrep.2014.09.034

Herrmann, J. A., Dahm, N. M., Ruiz, M. O., \& Brown, W. M. (2014). Temporal and Spatial Distribution of Tick-Borne Disease Cases among Humans and Canines in Illinois (20002009). Environmental Health Insights, 8s2, EHI.S16017. https://doi.org/10.4137/EHI.S16017

Holley, R. W., Apgar, J., Everett, G. A., Madison, J. T., Marquisee, M., Merrill, S. H., Penswick, J. R., \& Zamir, A. (1965). Structure of a Ribonucleic Acid. Science, 147(3664), 14621465. https://doi.org/10.1126/science.147.3664.1462

Hooper, L. V., \& Gordon, J. I. (2001). Commensal Host-Bacterial Relationships in the Gut. Science, 292(5519), 1115-1118. https://doi.org/10.1126/science.1058709 
Hosokawa, T., Koga, R., Kikuchi, Y., Meng, X.-Y., \& Fukatsu, T. (2010a). Wolbachia as a bacteriocyte-associated nutritional mutualist. Proceedings of the National Academy of Sciences, 107(2), 769-774. https://doi.org/10.1073/pnas.0911476107

Hosokawa, T., Koga, R., Kikuchi, Y., Meng, X.-Y., \& Fukatsu, T. (2010b). Wolbachia as a bacteriocyte-associated nutritional mutualist. Proceedings of the National Academy of Sciences, 107(2), 769-774. https://doi.org/10.1073/pnas.0911476107

Hunter, D. J., Torkelson, J. L., Bodnar, J., Mortazavi, B., Laurent, T., Deason, J., Thephavongsa, K., \& Zhong, J. (2015). The Rickettsia Endosymbiont of Ixodes pacificus Contains All the Genes of De Novo Folate Biosynthesis. PLOS ONE, 10(12), e0144552. https://doi.org/10.1371/journal.pone.0144552

Jackson, W. L. (2018). Mammalian meat allergy following a tick bite: A case report. Oxford Medical Case Reports, 2018(2). https://doi.org/10.1093/omcr/omx098

Jasinskas, A., Zhong, J., \& Barbour, A. G. (2007). Highly Prevalent Coxiella sp. Bacterium in the Tick Vector Amblyomma americanum. Applied and Environmental Microbiology, 73(1), 334-336. https://doi.org/10.1128/AEM.02009-06

Jeffries, C. L., \& Walker, T. (2016). Wolbachia Biocontrol Strategies for Arboviral Diseases and the Potential Influence of Resident Wolbachia Strains in Mosquitoes. Current Tropical Medicine Reports, 3(1), 20-25. https://doi.org/10.1007/s40475-016-0066-2

Jongejan, F., \& Uilenberg, G. (2004). The global importance of ticks. Parasitology, 129(S1), S3S14. https://doi.org/10.1017/S0031182004005967

Kirkness, E. F., Haas, B. J., Sun, W., Braig, H. R., Perotti, M. A., Clark, J. M., Lee, S. H., Robertson, H. M., Kennedy, R. C., Elhaik, E., Gerlach, D., Kriventseva, E. V., Elsik, C. G., Graur, D., Hill, C. A., Veenstra, J. A., Walenz, B., Tubio, J. M. C., Ribeiro, J. M. C., 
... Pittendrigh, B. R. (2010). Genome sequences of the human body louse and its primary endosymbiont provide insights into the permanent parasitic lifestyle. Proceedings of the National Academy of Sciences, 107(27), 12168-12173. https://doi.org/10.1073/pnas.1003379107

Klyachko, O., Stein, B. D., Grindle, N., Clay, K., \& Fuqua, C. (2007). Localization and Visualization of a Coxiella-Type Symbiont within the Lone Star Tick, Amblyomma americanum. Applied and Environmental Microbiology, 73(20), 6584-6594. https://doi.org/10.1128/AEM.00537-07

Kurlovs, A. H., Li, J., Cheng, D., \& Zhong, J. (2014). Ixodes pacificus Ticks Maintain Embryogenesis and Egg Hatching after Antibiotic Treatment of Rickettsia Endosymbiont. PLoS ONE, 9(8), e104815. https://doi.org/10.1371/journal.pone.0104815

Kurtti, T. J., Felsheim, R. F., Burkhardt, N. Y., Oliver, J. D., Heu, C. C., \& Munderloh, U. G. (2015). Rickettsia buchneri sp. Nov., a rickettsial endosymbiont of the blacklegged tick Ixodes scapularis. International Journal of Systematic and Evolutionary Microbiology, 65(Pt_3), 965-970. https://doi.org/10.1099/ijs.0.000047

Lalzar, I., Harrus, S., Mumcuoglu, K. Y., \& Gottlieb, Y. (2012). Composition and Seasonal Variation of Rhipicephalus turanicus and Rhipicephalus sanguineus Bacterial Communities. Applied and Environmental Microbiology, 78(12), 4110-4116. https://doi.org/10.1128/AEM.00323-12

Lo, N., Beninati, T., Sassera, D., Bouman, E. A. P., Santagati, S., Gern, L., Sambri, V., Masuzawa, T., Gray, J. S., Jaenson, T. G. T., Bouattour, A., Kenny, M. J., Guner, E. S., Kharitonenkov, I. G., Bitam, I., \& Bandi, C. (2006). Widespread distribution and high 
prevalence of an alpha-proteobacterial symbiont in the tick Ixodes ricinus. Environmental Microbiology, 8(7), 1280-1287. https://doi.org/10.1111/j.1462-2920.2006.01024.x

Macaluso, K. R., Soneshine, D. E., Ceraul, S. M., \& Azad, A. F. (2002). Rickettsial Infection in Dermacentor variabilis (Acari: Ixodidae) Inhibits Transovarial Transmission of a Second Rickettsia. Journal of Medical Entomology, 39(6), 809-813.

Magnúsdóttir, S., Ravcheev, D., de Crécy-Lagard, V., \& Thiele, I. (2015). Systematic genome assessment of B-vitamin biosynthesis suggests co-operation among gut microbes. Frontiers in Genetics, 6. https://doi.org/10.3389/fgene.2015.00148

Margulies, M., Egholm, M., Altman, W. E., Attiya, S., Bader, J. S., Bemben, L. A., Berka, J., Braverman, M. S., Chen, Y.-J., Chen, Z., Dewell, S. B., Du, L., Fierro, J. M., Gomes, X. V., Godwin, B. C., He, W., Helgesen, S., Ho, C. H., Irzyk, G. P., ... Rothberg, J. M. (2005). Genome sequencing in microfabricated high-density picolitre reactors. Nature, 437(7057), 376-380. https://doi.org/10.1038/nature03959

Mariconti, M., Epis, S., Gaibani, P., Dalla Valle, C., Sassera, D., Tomao, P., Fabbi, M., Castelli, F., Marone, P., Sambri, V., Bazzocchi, C., \& Bandi, C. (2012). Humans parasitized by the hard tick Ixodes ricinus are seropositive to Midichloria mitochondrii: Is Midichloria a novel pathogen, or just a marker of tick bite? Pathogens and Global Health, 106(7), 391396. https://doi.org/10.1179/2047773212Y.0000000050

Maxam, A. M., \& Gilbert, W. (1977). A new method for sequencing DNA. Proceedings of the National Academy of Sciences, 74(2), 560-564. https://doi.org/10.1073/pnas.74.2.560

McCutcheon, J. P., \& Moran, N. A. (2012). Extreme genome reduction in symbiotic bacteria. Nature Reviews Microbiology, 10(1), 13-26. https://doi.org/10.1038/nrmicro2670 
McLean, Donald M., \& Donahue, W. L. (1959). Powassan Virus: Isolation of Virus from a Fatal Case of Encephalitis. Canadian Medical Association Journal, 80(9), 708-711.

McLean, Donald M, \& Larke, B. (1963). Powassan and Silverwater Viruses: Ecology of Two Ontario Arboviruses. JAMA, 183(9), 189. https://doi.org/10.1001/jama.1963.03700090149091

McLean, DONALD M, Mahalingam, S., \& Wilson, W. E. (1964). Powassan Virus: Summer Infection Cycle, 1964.

Meyer, F., Paarmann, D., D’Souza, M., Olson, R., Glass, E., Kubal, M., Paczian, T., Rodriguez, A., Stevens, R., Wilke, A., Wilkening, J., \& Edwards, R. (2008). The metagenomics RAST server - a public resource for the automatic phylogenetic and functional analysis of metagenomes. BMC Bioinformatics, 9(1), 386. https://doi.org/10.1186/1471-2105-9386

Michalkova, V., Benoit, J. B., Weiss, B. L., Attardo, G. M., \& Aksoy, S. (2014). Vitamin B6 Generated by Obligate Symbionts Is Critical for Maintaining Proline Homeostasis and Fecundity in Tsetse Flies. Applied and Environmental Microbiology, 80(18), 5844-5853. https://doi.org/10.1128/AEM.01150-14

Moreno, C. X., Moy, F., Daniels, T. J., Godfrey, H. P., \& Cabello, F. C. (2006). Molecular analysis of microbial communities identified in different developmental stages of Ixodes scapularis ticks from Westchester and Dutchess Counties, New York. Environmental Microbiology, 8(5), 761-772. https://doi.org/10.1111/j.1462-2920.2005.00955.x

Nakao, R., Abe, T., Nijhof, A. M., Yamamoto, S., Jongejan, F., Ikemura, T., \& Sugimoto, C. (2013). A novel approach, based on BLSOMs (Batch Learning Self-Organizing Maps), to 
the microbiome analysis of ticks. The ISME Journal, 7(5), 1003-1015. https://doi.org/10.1038/ismej.2012.171

Narasimhan, S., \& Fikrig, E. (2015). Tick microbiome: The force within. Trends in Parasitology, 31(7), 315-323. https://doi.org/10.1016/j.pt.2015.03.010

Narasimhan, S., Rajeevan, N., Liu, L., Zhao, Y. O., Heisig, J., Pan, J., Eppler-Epstein, R., DePonte, K., Fish, D., \& Fikrig, E. (2014). Gut Microbiota of the Tick Vector Ixodes scapularis Modulate Colonization of the Lyme Disease Spirochete. Cell Host \& Microbe, 15(1), 58-71. https://doi.org/10.1016/j.chom.2013.12.001

Niebylski, M. L., Schrumpf, M. E., Burgdorfer, W., Fischer, E. R., Gage, K. L., \& Schwan, T. G. (1997). Rickettsia peacockii sp. Nov., a New Species Infecting Wood Ticks, Demacentor andersoni, in Western Montana? INT.J. SYST. BACTERIOL., 7.

Nikoh, N., Hosokawa, T., Moriyama, M., Oshima, K., Hattori, M., \& Fukatsu, T. (2014). Evolutionary origin of insect-Wolbachia nutritional mutualism. Proceedings of the National Academy of Sciences, 111(28), 10257-10262. https://doi.org/10.1073/pnas.1409284111

Noda, H., Munderloh, U. G., \& Kurtti, T. J. (1997). Endosymbionts of ticks and their relationship to Wolbachia spp. And tick-borne pathogens of humans and animals. Applied and Environmental Microbiology, 63(10), 3926-3932. https://doi.org/10.1128/AEM.63.10.3926-3932.1997

Nogge, G. (1976). Sterility in tsetse flies (Glossina morsitans Westwood) caused by loss of symbionts. Experientia, 32, 995-996. https://doi.org/10.1007/BF01933932 
Nováková, E., Hypša, V., \& Moran, N. A. (2009). Arsenophonus, an emerging clade of intracellular symbionts with a broad host distribution. BMC Microbiology, 9(1), 143. https://doi.org/10.1186/1471-2180-9-143

O’Brien, C. A., Hall-Mendelin, S., Hobson-Peters, J., Deliyannis, G., Allen, A., Lew-Tabor, A., Rodriguez-Valle, M., Barker, D., Barker, S. C., \& Hall, R. A. (2018). Discovery of a novel iflavirus sequence in the eastern paralysis tick Ixodes holocyclus. Archives of Virology, 163(9), 2451-2457. https://doi.org/10.1007/s00705-018-3868-9

Pachebat, J. A., van Keulen, G., Whitten, M. M. A., Girdwood, S., Del Sol, R., Dyson, P. J., \& Facey, P. D. (2013). Draft Genome Sequence of Rhodococcus rhodnii Strain LMG5362, a Symbiont of Rhodnius prolixus (Hemiptera, Reduviidae, Triatominae), the Principle Vector of Trypanosoma cruzi. Genome Announcements, 1(3), e00329-13, 1/3/e00329-13. https://doi.org/10.1128/genomeA.00329-13

Petrosino, J. F., Highlander, S., Luna, R. A., Gibbs, R. A., \& Versalovic, J. (2009). Metagenomic Pyrosequencing and Microbial Identification. Clinical Chemistry, 55(5), 856-866. https://doi.org/10.1373/clinchem.2008.107565

Phan, J. N., Lu, C. R., Bender, W. G., Smoak, R. M., \& Zhong, J. (2011). Molecular Detection and Identification of Rickettsia Species in Ixodes pacificus in California. Vector-Borne and Zoonotic Diseases, 11(7), 957-961. https://doi.org/10.1089/vbz.2010.0077

Piesman, J., \& Eisen, L. (2008). Prevention of Tick-Borne Diseases. Annual Review of Entomology, 53(1), 323-343. https://doi.org/10.1146/annurev.ento.53.103106.093429

Qiu, Y., Nakao, R., Ohnuma, A., Kawamori, F., \& Sugimoto, C. (2014). Microbial Population Analysis of the Salivary Glands of Ticks; A Possible Strategy for the Surveillance of 
Bacterial Pathogens. PLoS ONE, 9(8), e103961.

https://doi.org/10.1371/journal.pone.0103961

Quail, M., Smith, M. E., Coupland, P., Otto, T. D., Harris, S. R., Connor, T. R., Bertoni, A., Swerdlow, H. P., \& Gu, Y. (2012). A tale of three next generation sequencing platforms: Comparison of Ion torrent, pacific biosciences and illumina MiSeq sequencers. BMC Genomics, 13(1), 341. https://doi.org/10.1186/1471-2164-13-341

Rio, R. V. M., Symula, R. E., Wang, J., Lohs, C., Wu, Y., Snyder, A. K., Bjornson, R. D., Oshima, K., Biehl, B. S., Perna, N. T., Hattori, M., \& Aksoy, S. (2012). Insight into the Transmission Biology and Species-Specific Functional Capabilities of Tsetse (Diptera: Glossinidae) Obligate Symbiont Wigglesworthia. MBio, 3(1), e00240-11. https://doi.org/10.1128/mBio.00240-11

Ross, B. D., Hayes, B., Radey, M. C., Lee, X., Josek, T., Bjork, J., Neitzel, D., Paskewitz, S., Chou, S., \& Mougous, J. D. (2018). Ixodes scapularis does not harbor a stable midgut microbiome. The ISME Journal, 12(11), 2596-2607. https://doi.org/10.1038/s41396-0180161-6

Said, H. M. (2011). Intestinal absorption of water-soluble vitamins in health and disease. Biochemical Journal, 437(3), 357-372. https://doi.org/10.1042/BJ20110326

Salter, S. J., Cox, M. J., Turek, E. M., Calus, S. T., Cookson, W. O., Moffatt, M. F., Turner, P., Parkhill, J., Loman, N. J., \& Walker, A. W. (2014). Reagent and laboratory contamination can critically impact sequence-based microbiome analyses. BMC Biology, 12(1), 87. https://doi.org/10.1186/s12915-014-0087-z 
Samuel, W. M., \& Trainer, D. O. (1970). Ablyomma (Acarina: Ixodidae) on White-Tailed Deer, Odocoileus virginianus (Zimmermann), from South Texas with Implications for Theileriasis. Journal of Medical Entomology, 7(5), 567-574.

Sanger, F., Nicklen, S., \& Coulson, A. R. (1977). DNA sequencing with chain-terminating inhibitors. Proceedings of the National Academy of Sciences, 74(12), 5463-5467. https://doi.org/10.1073/pnas.74.12.5463

Santos-Garcia, D., Juravel, K., Freilich, S., Zchori-Fein, E., Latorre, A., Moya, A., Morin, S., \& Silva, F. J. (2018). To B or Not to B: Comparative Genomics Suggests Arsenophonus as a Source of B Vitamins in Whiteflies. Frontiers in Microbiology, 9, 1-16.

Sasaki-Fukatsu, K., Koga, R., Nikoh, N., Yoshizawa, K., Kasai, S., Mihara, M., Kobayashi, M., Tomita, T., \& Fukatsu, T. (2006). Symbiotic Bacteria Associated with Stomach Discs of Human Lice. Applied and Environmental Microbiology, 72(11), 7349-7352. https://doi.org/10.1128/AEM.01429-06

Schabereiter-Gurtner, C., Lubitz, W., \& Rölleke, S. (2003). Application of broad-range 16S rRNA PCR amplification and DGGE fingerprinting for detection of tick-infecting bacteria. Journal of Microbiological Methods, 52(2), 251-260. https://doi.org/10.1016/S0167-7012(02)00186-0

Schadt, E. E., Turner, S., \& Kasarskis, A. (2010). A window into third-generation sequencing. Human Molecular Genetics, 19(R2), R227-R240. https://doi.org/10.1093/hmg/ddq416

Shelton, A. N., Seth, E. C., Mok, K. C., Han, A. W., Jackson, S. N., Haft, D. R., \& Taga, M. E. (2019). Uneven distribution of cobamide biosynthesis and dependence in bacteria predicted by comparative genomics. The ISME Journal, 13(3), 789-804. https://doi.org/10.1038/s41396-018-0304-9 
Smith, T. A., Driscoll, T., Gillespie, J. J., \& Raghavan, R. (2015a). A Coxiella-Like Endosymbiont Is a Potential Vitamin Source for the Lone Star Tick. Genome Biology and Evolution, 7(3), 831-838. https://doi.org/10.1093/gbe/evv016

Smith, T. A., Driscoll, T., Gillespie, J. J., \& Raghavan, R. (2015b). A Coxiella-Like Endosymbiont Is a Potential Vitamin Source for the Lone Star Tick. Genome Biology and Evolution, 7(3), 831-838. https://doi.org/10.1093/gbe/evv016

Snyder, A. K., Deberry, J. W., Runyen-Janecky, L., \& Rio, R. V. M. (2010). Nutrient provisioning facilitates homeostasis between tsetse fly (Diptera: Glossinidae) symbionts. Proceedings of the Royal Society B: Biological Sciences, 277(1692), 2389-2397. https://doi.org/10.1098/rspb.2010.0364

Soneshine, D. E. (1991). Biology of Ticks (1st ed., Vol. 1). Oxford University. Spolidorio, M. G., Labruna, M. B., Mantovani, E., Brandão, P. E., Richtzenhain, L. J., \& Yoshinari, N. H. (2010). Novel Spotted Fever Group Rickettsiosis, Brazil. Emerging Infectious Diseases, 16(3), 521-523. https://doi.org/10.3201/eid1603.091338

Sprong, H., Azagi, T., Hoornstra, D., Nijhof, A. M., Knorr, S., Baarsma, M. E., \& Hovius, J. W. (2018). Control of Lyme borreliosis and other Ixodes ricinus-borne diseases. Parasites \& Vectors, 11(1), 145. https://doi.org/10.1186/s13071-018-2744-5

Subramanian, G., Sekeyova, Z., Raoult, D., \& Mediannikov, O. (2012). Multiple tick-associated bacteria in Ixodes ricinus from Slovakia. Ticks and Tick-Borne Diseases, 3(5-6), 406410. https://doi.org/10.1016/j.ttbdis.2012.10.001

Telford III, S., Armstrong, P. M., Katavolos, P., \& Foppa, I. (1997). A New Tick-borne Encephalitis-like Virus Infecting New England Deer Ticks, Ixodes dammini. Emerging Infectious Diseases, 3(2), 165-170. https://doi.org/10.3201/eid0302.970209 
Thapa, S., Zhang, Y., \& Allen, M. S. (2019). Effects of temperature on bacterial microbiome composition in Ixodes scapularis ticks. MicrobiologyOpen, 8(5), e00719. https://doi.org/10.1002/mbo3.719

Thomas, L. A., Kennedy, R. C., \& Eklund, C. M. (1960). Isolation of a Virus Closely Related to Powassan Virus from Dermacentor andersoni Collected along North Cache la Poudre River, Colo. Proceedings of the Society for Experimental Biology and Medicine, 104(2), 355-359.

Tokarz, R., Sameroff, S., Tagliafierro, T., Jain, K., Williams, S. H., Cucura, D. M., Rochlin, I., Monzon, J., Carpi, G., Tufts, D., Diuk-Wasser, M., Brinkerhoff, J., \& Lipkin, W. I. (2018). Identification of Novel Viruses in Amblyomma americanum, Dermacentor variabilis, and Ixodes scapularis Ticks. MSphere, 3(2), e00614-17, /msphere/3/2/mSphere0614-17.atom. https://doi.org/10.1128/mSphere.00614-17

Travanty, N. V., Ponnusamy, L., Kakumanu, M. L., Nicholson, W. L., \& Apperson, C. S. (2019). Diversity and structure of the bacterial microbiome of the American dog tick, Dermacentor variabilis, is dominated by the endosymbiont Francisella. Symbiosis, 79, 239-250.

Trout Fryxell, R. T., \& DeBruyn, J. M. (2016). The Microbiome of Ehrlichia-Infected and Uninfected Lone Star Ticks (Amblyomma americanum). PLOS ONE, 11(1), e0146651. https://doi.org/10.1371/journal.pone.0146651

van Dijk, E. L., Auger, H., Jaszczyszyn, Y., \& Thermes, C. (2014). Ten years of next-generation sequencing technology. Trends in Genetics, 30(9), 418-426.

https://doi.org/10.1016/j.tig.2014.07.001 
Van Treuren, W., Ponnusamy, L., Brinkerhoff, R. J., Gonzalez, A., Parobek, C. M., Juliano, J. J., Andreadis, T. G., Falco, R. C., Ziegler, L. B., Hathaway, N., Keeler, C., Emch, M., Bailey, J. A., Roe, R. M., Apperson, C. S., Knight, R., \& Meshnick, S. R. (2015). Variation in the Microbiota of Ixodes Ticks with Regard to Geography, Species, and Sex. Applied and Environmental Microbiology, 81(18), 6200-6209. https://doi.org/10.1128/AEM.01562-15

Vandegrift, K. J., \& Kapoor, A. (2019). The Ecology of New Constituents of the Tick Virome and Their Relevance to Public Health. Viruses, 11(6), 529. https://doi.org/10.3390/v11060529

VanInsberghe, D., Maas, K. R., Cardenas, E., Strachan, C. R., Hallam, S. J., \& Mohn, W. W. (2015). Non-symbiotic Bradyrhizobium ecotypes dominate North American forest soils. The ISME Journal, 9(11), 2435-2441. https://doi.org/10.1038/ismej.2015.54

Varela, A. S., Moore, V. A., \& Little, S. E. (2004). Disease Agents in Amblyomma americanum from Northeastern Georgia. Journal of Medical Entomology, 41(4), 753-759. https://doi.org/10.1603/0022-2585-41.4.753

Vayssier-Taussat, M., Moutailler, S., Michelet, L., Devillers, E., Bonnet, S., Cheval, J., Hébert, C., \& Eloit, M. (2013). Next Generation Sequencing Uncovers Unexpected Bacterial Pathogens in Ticks in Western Europe. PLoS ONE, 8(11), e81439. https://doi.org/10.1371/journal.pone.0081439

Weiss, B., \& Aksoy, S. (2011). Microbiome influences on insect host vector competence. Trends in Parasitology, 27(11), 514-522. https://doi.org/10.1016/j.pt.2011.05.001

Williams-Newkirk, A. J., Rowe, L. A., Mixson-Hayden, T. R., \& Dasch, G. A. (2014). Characterization of the Bacterial Communities of Life Stages of Free Living Lone Star 
Ticks (Amblyomma americanum). PLoS ONE, 9(7), e102130.

https://doi.org/10.1371/journal.pone.0102130

Xia, H., Hu, C., Zhang, D., Tang, S., Zhang, Z., Kou, Z., Fan, Z., Bente, D., Zeng, C., \& Li, T. (2015). Metagenomic Profile of the Viral Communities in Rhipicephalus spp. Ticks from Yunnan, China. PLOS ONE, 1O(3), e0121609.

https://doi.org/10.1371/journal.pone.0121609

Zhang, X., Norris, D. E., \& Rasgon, J. L. (2011). Distribution and molecular characterization of Wolbachia endosymbionts and filarial nematodes in Maryland populations of the lone star tick (Amblyomma americanum): Wolbachia and nematode infection in the lone star tick. FEMS Microbiology Ecology, 77(1), 50-56. https://doi.org/10.1111/j.15746941.2011.01089.x

Zhang, X.-C., Yang, Z.-N., Lu, B., Ma, X.-F., Zhang, C.-X., \& Xu, H.-J. (2014). The composition and transmission of microbiome in hard tick, Ixodes persulcatus, during blood meal. Ticks and Tick-Borne Diseases, 5(6), 864-870.

https://doi.org/10.1016/j.ttbdis.2014.07.009

Zhong, J., Jasinskas, A., \& Barbour, A. G. (2007). Antibiotic Treatment of the Tick Vector Amblyomma americanum Reduced Reproductive Fitness. PLoS ONE, 2(5), e405. https://doi.org/10.1371/journal.pone.0000405

Zug, R., \& Hammerstein, P. (2015). Bad guys turned nice? A critical assessment of Wolbachia mutualisms in arthropod hosts: Wolbachia mutualisms in arthropods. Biological Reviews, 90(1), 89-111. https://doi.org/10.1111/brv.12098 